\title{
2018 AATS/ACC/SCAI/STS Expert Consensus Systems of Care Document: Operator and institutional recommendations and requirements for transcatheter aortic valve replacement
}

A joint report of the American Association for Thoracic Surgery, American College of Cardiology, Society for Cardiovascular Angiography and Interventions, and Society of Thoracic Surgeons

\section{Writing Committee Members:}

Joseph E. Bavaria, Co-chair, MD, FACC, FACS, ${ }^{a}$ Carl L. Tommaso, Co-chair, MD, FACC, MSCAI, ${ }^{\mathrm{b}}$ Ralph G. Brindis, MD, MPH, MACC, FSCAI, John D. Carroll, MD, FACC, MSCAI, ${ }^{c}$ G. Michael Deeb, MD, FACC, FACS, ${ }^{\mathrm{d}}$ Ted E. Feldman, MD, FACC, MSCAI, Thomas G. Gleason, MD, MS, FACC, FACS, ${ }^{a}$ Eric M. Horlick, MD, FSCAI, Clifford J. Kavinsky, MD, PhD, FACC, MSCAI, ${ }^{\mathrm{b}}$ Dharam J. Kumbhani, MD, SM, FACC, FSCAI ${ }^{\mathrm{c}}$ D. Craig Miller, MD, FACC, FACS, ${ }^{\mathrm{d}}$ A. Allen Seals, MD, FACC, David M. Shahian, MD, FACC, FACS, ${ }^{\text {a }}$ Richard J. Shemin, MD, FACC, FACS, ${ }^{a}$ Thoralf M. Sundt III, MD, FACC, FACS, ${ }^{d}$ and Vinod H. Thourani, MD, FACC, FACS ${ }^{\text {a }}$

\section{TABLE OF CONTENTS}

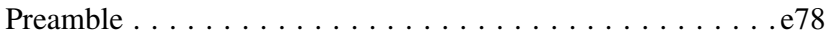

Relevant Policy Note. . . . . . . . . . . . . e78

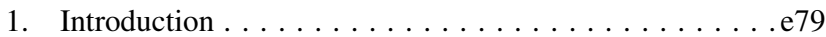

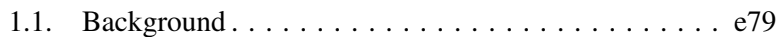

1.2. What Is New in the 2018 TAVR Operator and Institutional Requirements? . . . . . . . . . . e79

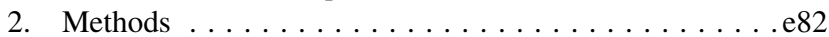

3. Structural Program Requirements . . . . . . . . . . e83

3.1. Procedural Volume................. e83

3.2. Multidisciplinary Team............. e 83

3.2.1. Knowledge Base and Skills . . . . . . . . e e83

3.3. Proceduralist Formalized Training . . . . . . . . . e85

3.4. Facilities and Institutional Resources . . . . . . . . e 855

4. Process Program Requirements. . . . . . . . . . . . e86

4.1. Patient Selection Requirements ........... e87 4.1.1. MDT Patient Case Conference

Requirements.............. e87

4.1.1.1. Operational Details. . . . . . . . e88

4.1.2. Patient Selection Considerations. . . . . . . e e88 4.1.2.1. Frailty, Cognition, QoL, Immobility, and Disability . . . . e91

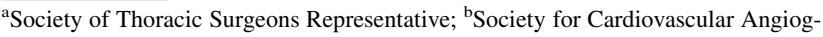
raphy and Interventions Representative; ${ }^{c}$ American College of Cardiology Representative; ${ }^{\mathrm{d}}$ American Association for Thoracic Surgery Representative.

This document was approved by the American Association for Thoracic Surgery (AATS) Council, American College of Cardiology (ACC) Clinical Policy Approval Committee, the Society for Cardiovascular Angiography and Interventions (SCAI) Board of Trustees, and the Society of Thoracic Surgeons (STS) Executive Committee in June 2018 .

The American Association for Thoracic Surgery requests that this document be cited as follows: Bavaria JE, Tommaso CL, Brindis RG, Carroll JD, Deeb GM, Feldman TE, Gleason TG, Horlick EM, Kavinsky CJ, Kumbhani DJ, Miller DC, Seals AA, Shahian DM, Shemin RJ, Sundt TM, Thourani VH. 2018 AATS/ACC/SCAI/STS Expert Consensus Systems of Care Document: operator and institutional requirements for transcatheter aortic valve replacement. J Thorac Cardiovasc Surg. 2019;157:e77-111.

This article is copublished in Catheterization and Cardiovascular Interventions, Journal of the American College of Cardiology, and The Annals of Thoracic Surgery.
}

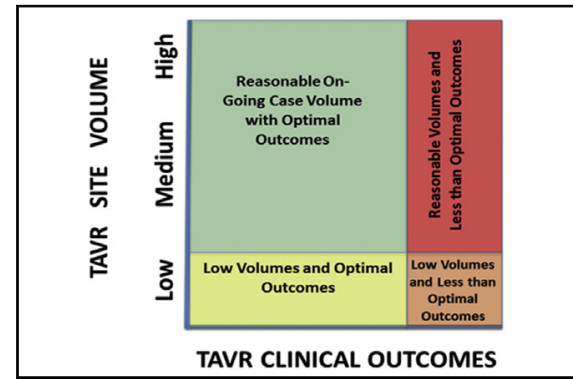

This schematic categorizes TAVR programs by their case volumes and clinical outcomes.

\section{Central Message}

TAVR has matured as a therapeutic option. The 2018 document provides additional quality metrics beyond operator skills. TAVR case volume requirements provide a structural measure to ensure foundational minimums.

See Commentary on page 868 .

Copies: This document is available on the World Wide Web site of the American Association for Thoracic Surgery, American College of Cardiology, Society for Cardiovascular Angiography and Interventions, Society of Thoracic Surgeons (www aats.org; www.acc.org; www.scai.org; www.sts.org). For copies of this document, please contact Elsevier Inc. Reprint Department, fax (212) 633-3820, e-mail reprints@elsevier.com.

Multiple copies, modification, alteration, enhancement, and/or distribution of this document are not permitted without the express permission of the American College of Cardiology. Requests may be completed online via the Elsevier site (https:// www.elsevier.com/about/our-business/policies/copyright/permissions).

J Thorac Cardiovasc Surg 2019;157:e77-111 $0022-5223 / \$ 36.00$

Copyright $(C) 2018$ by the American Association for Thoracic Surgery, the American College of Cardiology Foundation, the Wiley Periodicals, Inc., and the Society of Thoracic Surgeons

https://doi.org/10.1016/j.jtcvs.2018.07.001 


\subsubsection{Procedural Denial, Futility, QoL,} and Limited Life Expectancy. . . e91

4.1.2.3. Predictive Risk Models . . . . . . e93

4.2. SDM Requirements . . . . . . . . . . . . . . . . . . e93

5. Outcome Requirements . . . . . . . . . . . . . e93

6. Registry Requirements. . . . . . . . . . . . e95

7. Criteria for Establishing a TAVR Program and

Maintenance of Competence . . . . . . . . . . . . e97

7.1. Requirements and Recommendations for New TAVR

Programs. . . . . . . . . . . . . . . . e98

7.2. Requirements and Recommendations for Existing TAVR Programs. . . . . . . . . . . . . . e99

7.3. Requirements for SAVR . . . . . . . . . . . . . e100

7.3.1. SAVR-Only Programs . . . . . . . . . . e101

8. Compliance With Document Recommendations . . . . e102

9. Conclusions . . . . . . . . . . . . . . . . . . . . e103

References . . . . . . . . . . . . . . . . . . . . e103

Appendix 1 Measurement Statistical Approaches ..... . e106

Appendix 2 Author Relationships With Industry and Other Entities (RELEVANT)—2018 AATS/ACC/SCAI/ STS Expert Consensus Systems of Care Document: Operator and Institutional Recommendations and Requirements for Transcatheter Aortic Valve Replacement . . . e107

Appendix 3 Reviewer Relationships With Industry and Other Entities (RELEVANT)— 2018 AATS/ACC/SCAI/ STS Expert Consensus Systems of Care Document: Operator and Institutional Recommendations and Requirements for Transcatheter Aortic Valve Replacement . . . e109

Appendix 4 Abbreviations................e111

\section{PREAMBLE}

This multisocietal Expert Consensus Systems of Care document was commissioned by the American Association for Thoracic Surgery (AATS), the American College of Cardiology (ACC), the Society for Cardiovascular Angiography and Interventions (SCAI), and the Society of Thoracic Surgeons (STS). Expert Consensus Systems of Care documents are intended to summarize the position of these partnering organizations on the availability, delivery, organization, and quality of cardiovascular care.

With the rapid evolution and dissemination of transcatheter aortic valve replacement (TAVR) technology, it is imperative that the cardiovascular community work together to identify the criteria for performing these procedures safely and successfully. Such criteria serve to guide both practitioners and institutions in the development and maintenance of TAVR programs in the spirit of optimizing quality outcomes. The unique qualifications to participate in this field comprise specific interventional skills, high-tech equipment, collaborative clinical management, evolving approaches for alternative access, and multidisciplinary decision making.

The AATS, ACC, SCAI, and STS have joined together to provide recommendations for institutions and individuals to assess their potential for instituting and/or maintaining a high-quality TAVR program. The first multisocietal document on institutional and operator requirements for performing TAVR was published in $2012^{1}$ and is now updated to reflect the current evolution in practice and quality benchmarks.

A strong emphasis on a team-based approach for patient management remains unchanged. Where possible, the writing committee's recommendations are rooted in the robust data accrued from the STS/ACC Transcatheter Valve Therapies (TVT) registry.

The writing group has included a multimodal approach to quality measurement that allows the requirements to evolve in anticipation of newer treatment modalities; expansion to younger and lower-risk populations; and emerging evidence regarding patient outcomes, cost, cost-effectiveness, and durability.

\section{RELEVANT POLICY NOTE}

Recent developments in U.S. policy related to operator and institutional requirements have come to light as this document was being finalized. The committee wishes to communicate to all stakeholders the following key points.

1. The professional society operator and institutional requirements are intended to provide guidance and support for a large number of centers throughout the United States with a rational balance between patient access to TAVR therapy and quality outcomes. Questions regarding patient access to TAVR are complex and multifactorial and mirror similar barriers to access that exist in medical care in the United States. Primary care providers play a critical role in facilitating access to TAVR with recognition and diagnosis of valvular heart disease leading to referral for specialized care.

2. This document does not recommend that sites failing to meet all requirements should close their TAVR-surgical aortic valve repair (SAVR) programs. Rather, the committee recommends that all sites review their quarterly outcome reports and assess if they are within national benchmarks of acceptable quality of care. An accreditation process is one means to help ensure quality and also provide external review of programs.

3. The major threat to low-volume sites growing and achieving higher levels of experience is the opening of additional sites in the same geographic region. In 2017, 204 of the 525 U.S. sites performing TAVR were performing less than 50 TAVR procedures on an annual basis.

4. The expansion of indications for TAVR and the overall volume growth of TAVR in the United States may soon accelerate if patients who are at low risk for SAVR have the option for TAVR based on the results of ongoing clinical trials and potential U.S. Food and Drug Administration (FDA) approval. A plausible consequence of expanded indications for TAVR is that some programs offering both SAVR and TAVR will see SAVR volume fall below the required threshold. If this occurs, it is not the 
intent of the committee to have sites maintain SAVR volume by deviating from a shared decision making (SDM) process with patients and heart team guidance. The committee recommends that all sites should assess the quality of their SAVR programs using site performance metrics from STS and maintain a 2- to 3-star rating.

5. Many U.S. regions have a low population density with long distances to tertiary medical care. TAVR sites have opened in many of these regions, and it is important that they remain active if they can document acceptable quality even if they should fall below volume thresholds to maintain patient access to care.

6. This document presents the types and details of currently available outcome metrics that enable an objective assessment of site performance. Importantly, additional metrics are under development to make this a more comprehensive assessment, including alive and well at 1 year. The incorporation of these additional metrics will diminish the need to rely on raw volume numbers. Quarterly reports sent to sites by the STS/ACC TVT Registry include site data and national benchmarks that are updated regularly for TAVR. Similar quality assessment/quality improvement processes are well established in the STS Adult Cardiac Surgery Database for SAVR programs.

a. The metrics for assessment of TAVR site performance are not yet at a state of maturity compared with SAVR and the STS star rating system. Similar performance metrics are under development for TAVR by the STS/ACC and should be tested and implemented when feasible.

b. In addition, 1-year patient outcomes for both TAVR and SAVR are important for clinicians, patients, and the Centers for Medicare \& Medicaid Services (CMS). One-year outcomes have multiple determinants including patient characteristics, the immediate outcome of the procedure-surgery, post-procedure care, and perhaps most importantly, patient selection decision making. The 1-year composite outcome measure for TAVR that is under development by the STS/ACC includes alive-and-well assessment using the results of the change in the Kansas City Cardiomyopathy Questionnaire (KCCQ) score. The composite will reflect both the team's capabilities in selecting patients who stand to benefit most from TAVR and in not recommending TAVR when the risk-benefit ratio is unfavorable or futile.

c. All sites must submit accurate and complete data to ensure accurate quality assessment and to achieve the goals of these standards.

7. An additional important consideration is that transcatheter devices continue to evolve. There may not be a class effect with TAVR in terms of complication patterns such that device-specific data will be necessary to study outcomes.
8. The Duke Clinical Research Institute has performed a preliminary analysis of the most recent STS/ACC TVT Registry data that shows a clinically meaningful association of higher mortality and other major complications with site annual volume below the recommended threshold of 50 procedures/year. Further analysis of these data is needed to confirm these preliminary findings and to more fully understand the factors associated with these worse outcomes. This further analysis is also needed to assess why some low-volume sites have acceptable outcomes and others do not, and to understand if these sites improve over time. The committee feels that elimination of annual procedure volume requirements would result in a possibility of increased TAVR risk-adjusted mortality and major complications in the United States despite 5 consecutive years of improving outcomes.

a. The assessment of site performance with low annual volumes is a major statistical challenge. Low annual volumes of TAVR, as well as SAVR, require an increased scrutiny of quality assessment results because of wider confidence bands and greater variability of outcomes. New analytic methods need to be applied to achieve valid assessment of low-volume sites' performance. Using multiyear data from sites with low annual volumes is 1 approach to addressing this challenge.

\section{INTRODUCTION}

\subsection{Background}

The goal of the writing committee was to provide a quality framework for any center providing TAVR as a treatment option for aortic valve disease in the United States.

While this document specifically addresses TAVR requirements, it should be placed in a larger context and specifically address the broader goal of optimizing the care of all patients with severe aortic valve disease. Since publication of the original document in 2012, TAVR indications have been extended into groups of patients who are eligible for SAVR at intermediate to high risk; TAVR has also become an alternative to reoperation for those with severe bioprosthetic aortic valve degeneration. ${ }^{2-4}$ Programs are now evaluating a broad spectrum of patients who may be appropriate for either form of valve replacement (ie, TAVR and SAVR). The approval of a TAVR valve for a specific STS SAVR risk population does not necessarily mean that TAVR should be the chosen procedure for any particular patient in that population.

\subsection{What Is New in the 2018 TAVR Operator and Institutional Requirements?}

The writing committee recognizes that adequate TAVR outcomes data are now available, permitting an evolution from an exclusively prerequisite skills-based set of 
recommendations to an integration of actual TAVR quality and experience as the basis of qualifications for the performance of TAVR.

The primary objective of this updated document is to promote standards that will help centers achieve high-quality outcomes for patients who have clinically significant aortic valve disease.

Outlined in the following text are the most important new areas of emphasis within the updated document:

- The document focuses on the overall goal of improving patient outcomes at all sites and on providing guidance regarding the use of data and analyses. For example, sites whose risk-adjusted outcomes are worse than expected for their case mix, based on the national benchmark population, should initiate robust performance improvement programs, which are often facilitated by external review and recommendations.

- The writing committee has produced a document that is forward thinking, combining site process and outcome performance metrics that can be updated with data reflecting evolving patient characteristics, changing procedure technologies and techniques, and improving short- and long-term outcomes. Other structural operator and institutional requirements are not expected to change substantially as they reflect basic infrastructure needs and fundamental clinical skills and experience.

- With over 580 active both TAVR-SAVR sites in the United States, most patients now have reasonable geographic access to care. Other barriers to access that relate to broader and more fundamental issues in the U.S. healthcare system cannot be addressed in this document.

- The writing committee does not consider the requirements or recommendations in this document to exceed the capabilities of most centers, currently or with reasonable modifications, and the recommendations or requirements are not meant to exclude existing or future centers.

- TAVR continues to be a dynamic, evolving therapy. The phases of TAVR development and distribution in the U.S. healthcare system as well as the transitions in operator and institutional requirements are presented in Figure 1. The TVT Registry has gathered data from over 100,000 patients who have received TAVR. These data are now focused in 3 new directions within the 2018 document:

1. Emphasis on Direct Measures of Quality of Care: This 2018 document provides additional quality metrics that complement requirements presented in the 2012 document. ${ }^{1}$ TAVR case-volume requirements ensure foundational data minimums needed for measurement of quality outcomes.

a. Beginning in 2018, direct measures of quality of care for both TAVR and SAVR programs will be emphasized. Two types of quality measures are already available for TAVR program evaluation:

i. Unadjusted site-specific outcomes in comparison with national benchmarks; and

ii. Risk-adjusted in-hospital outcomes and 30-day TAVR mortality to account for increasing casemix variations across sites.

b. In the next phase, we propose the incorporation of additional validated, risk-adjusted measures, including 1-year and composite outcomes. These will provide sites with a better understanding of their program's performance and guidance for improving the quality of patient care and selection. This approach has been developed for SAVR over decades of data gathering, analysis, and validation.

c. Quality outcome measures are reported to sites using the TVT database for TAVR and the STS database for SAVR.

d. Ultimately, the goal is to have similar quality outcome measures for both TAVR and SAVR. For TAVR, this will require the development, validation, and use of additional outcome metrics; for SAVR, long-term outcomes such as 1-year survival and impact on quality of life (QoL) will be required.

e. Over time, volume requirements for TAVR and SAVR will be used primarily to ensure that a program has adequate ongoing volume to provide statistically reliable quality metrics and maintain effective processes of care.

2. Emphasis on the Care of All Patients With Aortic Valve Disease: The focus of this document is on treating all patients with aortic valve disease and therefore offering all forms of treatment, including TAVR, SAVR, medical care, and palliative care. Some sites in the United States offer only SAVR, as discussed subsequently in this document. Of particular concern is how patients at these sites will be informed of their possible eligibility for TAVR. This process of informing patients includes possible referral to TAVR sites for consultation and fully informed SDM.

3. Emphasis on the Incorporation of SDM: This 2018 document recommends that sites incorporate methods and processes promoting patient- and family-centered care with informed SDM. This recommendation goes beyond patient education and the traditional use of informed consent, which involves an explanation of generic risks and potential benefits. It specifically includes an individualized approach utilizing patient-specific, data-driven risk assessment; clear explanation of a patient's options; 


\begin{tabular}{|c|c|}
\hline $\begin{array}{l}\text { Early Investigative Phase of TAVR } \\
\text { - Very few research sites that are highly selected based } \\
\text { on meeting multipleoperator and institutional } \\
\text { requirements defined by industry. } \\
\text { - Active site monitoring by sponsor assessing and } \\
\text { adjudicating outcomes. } \\
\text { - Initial assessment of learning curve, definition and } \\
\text { determinants of outcomes, and development of } \\
\text { systems for training and site support by industry. } \\
\text { - Blueprint determined for technology and technique } \\
\text { improvements to address weaknesses and limitations } \\
\text { of first generation devices and delivery systems. }\end{array}$ & $\begin{array}{l}\text { Initial U.S. Commercial TAVR Roll-Out } \\
\text { Starting in } \mathbf{2 0 1 2} \\
\text { - Number of commercial sites rapidly grows. } \\
\text { - Site requirements specified by NCD with professional } \\
\text { society guidance and lessons learned from clinical } \\
\text { trials. } \\
\text { - Requirements are not directly related to TAVR but } \\
\text { surrogates representing required skills, experience, } \\
\text { and infrastructure. } \\
\text { - The heart team model introduced as a site } \\
\text { requirement as well as its importance for SAVR } \\
\text { programs. } \\
\text { - Participation in national registry required by CMS. }\end{array}$ \\
\hline $\begin{array}{l}\text { Mature State of TAVR and SAVR in } 2025 \\
\text { - Number of sites stable. Few SAVR only sites remain. } \\
\text { levels of risk, and access to newer technology. } \\
\text { - Requirements related to site performance with mature } \\
\text { risk-adjusted outcome measures. } \\
\text { - TAVR and SAVR requirements are harmonized. } \\
\text { Volume requirements only used to document a site's } \\
\text { maintenance of an efficient and experienced team } \\
\text { rather than a surrogate for quality. } \\
\text { - Long-term outcomes are well studied based on TVT } \\
\text { and STS databases of all treatment modalities and } \\
\text { used to guide patient selection and shared decision- } \\
\text { making. }\end{array}$ & $\begin{array}{l}\text { Commercial TAVR Steady State in } 2018 \\
\text { - Over } 550 \text { active sites representing the vast majority } \\
\text { of sites meeting NCD requirements. } \\
\text { - Updated site requirements are related to an } \\
\text { evolving process using TAVR outcomes with national } \\
\text { benchmarks from TVT Registry. } \\
\text { - TAVR volume requirements are temporarily used as } \\
\text { a surrogate for quality for all sites and continually for } \\
\text { sites climbing the early learning curve. } \\
\text { - Risk-adjusted direct outcome measures are } \\
\text { developed, validated, and introduced for TAVR to } \\
\text { replace volume. } \\
\text { - Shared decision-making promoted to enable } \\
\text { patients making informed decisions between } \\
\text { treatment options. }\end{array}$ \\
\hline
\end{tabular}

FIGURE 1. Evolution of site operator requirements for TAVR. This schematic shows the evolution of TAVR site and operator requirements, starting with the investigative phase, which is followed by 3 commercial phases. As of 2018 , the initial commercial phase has ended and TAVR is now in a steady state in which requirements can now be based predominantly on quality metrics, with volume being used only to demonstrate a program's ability to maintain a reasonable number of cases to measure quality (ie, as a process metric rather than as a surrogate outcome metric). TAVR, Transcatheter aortic valve replacement; NCD, National Coverage Determination; SAVR, surgical aortic valve replacement; $C M S$, Centers for Medicare \& Medicaid Services; TVT, Transcatheter Valve Therapies; STS, Society of Thoracic Surgeons.

the rationale for the recommendations of the multidisciplinary team (MDT); and the incorporation of patient preferences and values into patients' treatment decisions.

- Figure 2 shows the categorization of sites based on their TAVR volume and risk-adjusted outcome measures, such as the observed-to-expected ratio of an outcome measure (eg, risk-adjusted in-hospital, 30-day, and ultimately, 1year mortality). One goal of this 2018 document is to promote the ability of all centers to achieve both adequate volumes and acceptable outcomes (ie, the upper left quadrant in this schematic).

- Volume: It is anticipated that most low-volume sites will steadily increase their number of procedures due to the approval of moderate-risk patients for TAVR, FDA approval of additional indications for
TAVR usage, and ongoing aging of the U.S. population.

- Quality: Preliminary data from a new analysis show that there are many low-volume sites with seemingly acceptable outcomes; however, due to the low number of cases in such sites, the assessment of their outcomes is statistically challenging, resulting in substantial random sampling variation (ie, wide confidence intervals). The volume-outcome relationship and learning curve shown during the initial U.S. experience in TAVR require updating. Conversely, a few highervolume sites have suboptimal outcomes-an assessment that is more likely to be statistically valid. Irrespective of volume, sites with unacceptable outcomes are of concern and should immediately take corrective actions to improve their outcomes and processes. In-depth discussion of the statistical challenge 


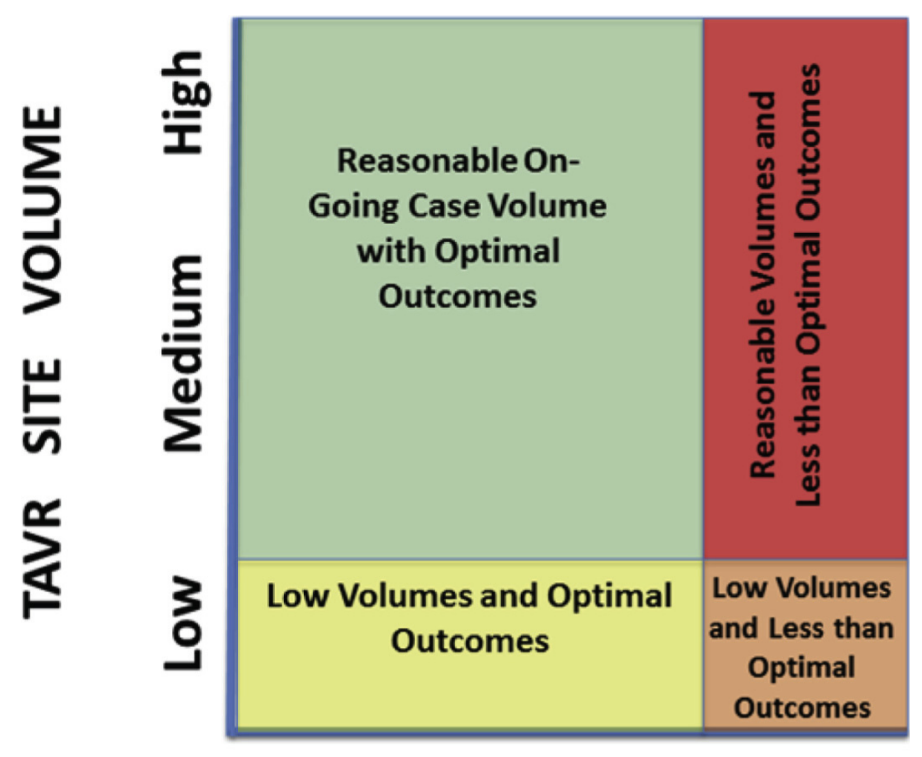

\section{TAVR CLINICAL OUTCOMES}

FIGURE 2. Categorization of sites on the basis of TAVR volume and outcome measures. This schematic categorizes TAVR programs by their case volumes and clinical outcomes. Most programs have sufficient case volumes to achieve technical competence and acceptable results, although these volumes may not be sufficient to allow statistically valid quality assessments. A few programs may have adequate volumes to meet TAVR requirements and ensure statistically valid quality assessment but still appear to have suboptimal performance. These programs need to take immediate actions to improve their outcomes as it is likely they are underperforming. Some programs with lower volumes appear to have acceptable outcomes, but because of their small sample sizes, their outcome data are less statistically reliable. These programs must continue to be vigilant in assessing their quality. Finally, some programs have low volume and less than optimal outcomes. Although these outcomes are statistically less certain, action should be undertaken immediately to further assess and improve quality. TAVR, Transcatheter aortic valve replacement.

of correctly identifying poorly performing TAVR programs with low annual volumes is presented in Appendix 1.

- This document specifies operator and institutional requirements and recommendations. Requirements are based on best available objective evidence and address issues of critical importance for delivering high-quality care. Recommendations are based on expert opinion and apply to important components of programs.

The characterization of quality using the Donabedian triad of structure, process, and outcomes measures is a reasonable framework for establishing TAVR quality. ${ }^{5}$ The 2006 Institute of Medicine report, "Performance Measurement: Accelerating Improvement," provides a framework for translating the need for assessment of performance in health care into measures of quality. ${ }^{6}$ The measures are related to the key periods of patient evaluation, procedure performance, postprocedure care, and assessment of medium-term outcomes. This document incorporates several measures into the proposed site requirements.

\section{METHODS}

This document is an update to the 2012 Multisociety (AATS, ACCF, SCAI, and STS) Expert Consensus Statement: Operator and Institutional
Requirements for Transcatheter Valve Repair and Replacement, Part 1: Transcatheter Aortic Valve Replacement. ${ }^{1}$ The writing committee was composed of representatives from the AATS, ACC, SCAI, and STS.

Partnering societies used the ACC's policy on relationships with industry and other entities (RWI) to author this document. To avoid actual, potential, or perceived conflict of interest that may arise as a result of industry relationships or personal interests among the writing committee, all members of the writing committee, as well as peer reviewers of the document, were asked to disclose all current healthcare-related relationships, including those existing up to 12 months before initiation of the writing effort. Because this document needed the input of clinical experts, leadership from the 4 partnering societies decided to allow an exception to the usual prohibition on clinical trial participation in industrysponsored trials provided there was no compensation involved. Activities involving a clinical trial as a steering committee member or principal investigator were not considered relevant relationships. Author and peer reviewer RWI pertinent to this document are disclosed in Appendixes 2 and 3. In addition, to ensure complete transparency, authors' comprehensive disclosure information (including RWI not pertinent to this document) is available online. The work of the writing committee was supported exclusively by the partnering societies without commercial support. The Chairs have no RWI and are responsible for the content of this document. The ACC disclosure policy for document development is available online. Writing committee members volunteered their time to this effort. Conference calls of the writing committee were confidential and attended only by writing committee members and relevant AATS/ ACC/SCAI/STS staff.

A public comment period was held to obtain further feedback. Following reconciliation of all comments and sign-off by the writing committee and oversight task force, this document was approved for publication by the approval bodies of the partnering societies. 


\section{STRUCTURAL PROGRAM REQUIREMENTS}

The structural measures of quality include the requirement that operators and institutions have the skills, experience, foundational TAVR and SAVR volume, and facilities that are fundamental to delivering TAVR and SAVR. These quality measures of program structure are outlined in Tables 1 and 2.

\subsection{Procedural Volume}

There are learning curves associated with TAVR..$^{7-9}$ For instance, nonfemoral TAVR involves an important learning process, with 30 to 45 cases needed to reach a plateau for procedure time and device success. ${ }^{10,11}$ Analysis of early STS/ACC TVT Registry data shows that the cumulative TAVR volume-outcome relationship is strong during the learning curve, which is expected given that this is a novel procedure with high risk in an elderly patient population. ${ }^{12}$ In their analysis, Carroll et al. ${ }^{12}$ noted that there was a steep slope for improved major outcomes in the first 100 cases.

TAVR case-volume requirements listed in this document ensure foundational data minimums needed to maintain program and operator effectiveness and efficiency as well as sufficient sample size for measurement of quality outcomes.

Sites that are not in the higher-volume/experienced tier programs may provide high-quality TAVR care, typically via the well-established transfemoral approach. This is especially relevant to the more geographically isolated locations and to underserved patient populations in the United States. The 2018 operator and institutional requirements support the ongoing activities of such sites. These programs should have an active quality assessment and improvement process. Higher-risk cases and those requiring more complex access at these low-volume sites should be referred to higher-volume centers with sufficient experience and expertise in complex or alternative-access cases.

\subsection{Multidisciplinary Team}

The defining principle of the MDT is an institutionally based joint cardiology and cardiac surgery effort. ${ }^{13,14}$ TAVR programs should only be established if this multidisciplinary partnership is present. Additional providers, including imaging physicians, anesthesiologists, nurses, social services, and administrative support personnel, are also necessary. A comprehensive MDT is mandatory for a TAVR program. ${ }^{15}$

The MDT should be supported using institutional resources and consists of physicians and medical personnel from many specialties with specific skills, including:

- Interventional cardiologist

- Cardiac surgeon

- Echocardiographic and radiographic image specialist
- Cardiovascular anesthesiologist

- Nurse practitioner/physician assistant for preprocedure and periprocedure care and MDT consults

- TAVR administrative coordinator/program navigator

- Institutionally supported data manager for STS/ACC TVT Registry

- Hospital administration representative

Additionally, the following comprise the essential consultative resources for the MDT:

- Electrophysiology capabilities for implantation of permanent pacemakers 24 hours/day, 7 days/week

- Neurology with a 24-hour/day, 7-day/week stroke team

- Renal medicine with dialysis capabilities

- Medical and palliative care for patients who are not TAVR or SAVR candidates

- Vascular surgery support

With increasing use of conscious sedation, the perfusion and operating room (OR) teams will not be necessary in many transfemoral procedures. ${ }^{16}$ Additionally, an anesthesiologist may not be present in some instances, depending on patient severity and the training and skillsets of other staff; however, anesthesia and hemodynamic support must nonetheless be readily available.

\subsubsection{Knowledge Base and Skills}

One of the cornerstones of the success of transcatheter valve programs is the partnership between cardiologists and cardiac surgeons, the underlying principle being that no one individual, group, or specialty possesses all of the necessary skills for optimal patient outcomes. ${ }^{13,17}$ The success of these programs depends on a group of professionals, each with his or her own skillset, working together to provide the best possible patient-centered care. $^{13,18}$

There are specific and unique cognitive and technical skills that are essential for all physicians for optimal performance of TAVR irrespective of specialty background. ${ }^{19,20}$ For the purpose of this document, the term "TAVR proceduralist" refers to either interventional cardiologists or cardiac surgeons. These clinicians should possess extensive knowledge of valvular heart disease (VHD), including the natural history of the disease, hemodynamics, appropriate diagnostics and imaging, optimal medical therapy (particularly of comorbidities), application and outcome for both TAVR and SAVR, procedural and perioperative care, and long-term follow-up. ${ }^{21}$

The ability to accurately interpret noninvasive imaging studies during patient evaluation, intraoperatively, in the immediate postoperative period, and at follow-up is critically important. The MDT should have access to expert imaging including echocardiographic interpretation skills for transthoracic and both 2- and 3-dimensional transesophageal 
TABLE 1. TAVR program performance requirements: Minimum quality benchmarks for TAVR sites

\begin{tabular}{|c|c|}
\hline \multicolumn{2}{|c|}{2018 Criteria } \\
\hline Primary outcome metrics & Performance requirement \\
\hline $\begin{array}{l}\text { In-hospital risk-adjusted } \\
\text { all-cause mortality }\end{array}$ & $\begin{array}{l}\text { - Based on } 95 \% \text { confidence } \\
\text { intervals and national } \\
\text { benchmark data, the program's } \\
\text { performance is "as expected" } \\
\text { or "better than expected." }\end{array}$ \\
\hline $\begin{array}{l}\text { 30-day risk-adjusted } \\
\text { all-cause mortality }\end{array}$ & $\begin{array}{l}\text { - Based on } 95 \% \text { confidence } \\
\text { intervals and national } \\
\text { benchmark data, the program's } \\
\text { performance is "as expected" } \\
\text { or "better than expected." }\end{array}$ \\
\hline $\begin{array}{l}\text { 30-day all-cause } \\
\text { neurological events, } \\
\text { including TIAs* }\end{array}$ & $\begin{array}{l}\text { - Funnel plots using } 95 \% \\
\text { (outlier) and/or } 90 \% \text { (warning) } \\
\text { limits to indicate that the } \\
\text { program's performance falls } \\
\text { within the selected boundaries }\end{array}$ \\
\hline $\begin{array}{l}\text { 30-day major vascular } \\
\text { complication* }\end{array}$ & $\begin{array}{l}\text { - Funnel plots using } 95 \% \\
\text { (outlier) and/or } 90 \% \text { (warning) } \\
\text { limits to indicate that the } \\
\text { program's performance falls } \\
\text { within the selected boundaries }\end{array}$ \\
\hline 30-day major bleeding* & $\begin{array}{l}\text { - Funnel plots using } 95 \% \\
\text { (outlier) and/or } 90 \% \text { (warning) } \\
\text { limits to indicate that the } \\
\text { program's performance falls } \\
\text { within the selected boundaries } \dagger\end{array}$ \\
\hline $\begin{array}{l}\text { 30-day moderate or } \\
\text { severe } \mathrm{AR}^{*}\end{array}$ & $\begin{array}{l}\text { - Funnel plots using } 95 \% \\
\text { (outlier) and/or } 90 \% \text { (warning) } \\
\text { limits to indicate that the } \\
\text { program's performance falls } \\
\text { within the selected boundaries }\end{array}$ \\
\hline \multicolumn{2}{|c|}{ Primary 1-Year Outcome Metrics (in development) } \\
\hline \multicolumn{2}{|c|}{ 1-year risk adjusted all-cause mortality } \\
\hline \multicolumn{2}{|c|}{$\begin{array}{l}\text { Patient-reported health status (KCCQ) at } 30 \text { days and } 1 \text { year } \\
\text { versus baseline }\end{array}$} \\
\hline $\begin{array}{l}\text { 30-day and 1-year risk-adju } \\
\text { (composite index) }\end{array}$ & lity and morbidity \\
\hline
\end{tabular}

TIA, Transient ischemic attack; $A R$, aortic regurgitation; $K C C Q$, Kansas City Cardiomyopathy Questionnaire. *Presently only in-hospital and, shortly, 30-day mortality outcomes are risk-adjusted. Therefore, other outcomes are not risk-adjusted and need to be interpreted in the context of a program's constellation of patients with their spectrum of characteristics that impact outcomes. $\dagger$ As available for reporting.

echocardiography studies. Expertise in interpretation of computed tomography (CT) scans, including gated CT angiograms of the heart and iliofemoral vessels, is essential for understanding anatomic issues such as:

- The size, shape, degree, and distribution of calcium in the aortic valve annulus

- The presence and degree of calcium in the left ventricular (LV) outflow tract and aorta

- The size and morphology of the sinuses of Valsalva
TABLE 2. TAVR program performance requirements: Additional criteria to be used as a roadmap for quality improvement for each TAVR program

\begin{tabular}{ll}
\hline \multicolumn{1}{c}{2018 Criteria } \\
\hline Time frame & \multicolumn{1}{c}{ Outcome metrics } \\
\hline In-hospital & Procedure aborted \\
& Conversion to open heart surgery \\
& Unplanned institution of mechanical \\
& circulatory support \\
& Valve-in-valve TAVR during procedure \\
& Cardiac arrest \\
& Annular dissection \\
& Aortic disruption/dissection \\
& Device embolization \\
& Device implant success \\
& AKIN class stage 3 \\
& New pacemaker \\
30-day all-cause rehospitalization rate \\
Patient-reported health status (KCCQ \\
score) of surviving patients at 30 \\
days: an increase in the KCCQ \\
composite score $\geq 10$ points relative \\
to baseline \\
All-cause mortality \\
Patient-reported health status (KCCQ \\
score) of surviving patients at 1 year: \\
an increase in the KCCQ composite \\
score $\geq 10$ points relative to baseline \\
\hline 1-year
\end{tabular}

$T A V R$, Transcatheter aortic valve replacement; $A K I N$, Acute Kidney Injury Network; $K C C Q$, Kansas City Cardiomyopathy Questionnaire.

- Hypertrophy of the basal septum

- The location of the coronary arteries

- Calcification, dilatation, angulation, and tortuosity of the aorta

- Calcification, tortuosity, and caliber of the iliofemoral and brachiocephalic vessels. ${ }^{20,21}$

There should also be mastery of post-acquisition CT software for detailed analysis of the heart, aorta, and peripheral vessels.

Essential technical skillsets required for the safe and effective performance of TAVR procedures include but are not limited to:

- An understanding of radiation safety, optimal fluoroscopic imaging, and the use of contrast agents

- The use of hemodynamic monitoring systems

- Large-bore vascular access and closure techniques

- Balloon dilatation of the aortic valve

- Advanced wire skills, including knowledge of the full array of guidewire technologies applicable to TAVR

- Retrieval devices and techniques

- Peripheral vascular diagnostic and interventional techniques, including use of covered stents

- Abdominal and thoracic endovascular aortic repair 
- Coronary diagnostic and interventional techniques

- Percutaneous LV mechanical support devices

- Percutaneous closure of paravalvular leaks

- The ability to rapidly diagnose and treat rhythm disturbances

- An understanding of the indications for placement of permanent pacemakers in the TAVR setting

Surgeons should have experience with surgical vascular access and postprocedural repair techniques, particularly pertaining to the axillary, subclavian, and carotid arteries as well as transapical, transaortic, and other alternative access approaches when the transfemoral arterial approach is not possible. It is understood that the entire spectrum of cognitive and technical skillsets required may not be possessed by a single individual TAVR proceduralist but that the combined skills of the procedural team will be complementary and synergistic.

\subsection{Proceduralist Formalized Training}

The field of percutaneous repair of cardiac structural abnormalities has advanced rapidly in the last decade. Training for TAVR should occur by 1 of 2 pathways: (1) a formal training program incorporated into cardiology fellowship or cardiovascular surgical residency; or (2) formal proctorship wherein an established interventional cardiologist or cardiac surgeon participates in an established TAVR program under the tutelage of an experienced team.

Ongoing education courses with didactics focused on new concepts of TAVR, hands-on experience with devicespecific equipment, simulation, viewing live cases performed by experienced operators in an interactive format, experienced device-specific proctors, and formalized fellowship training should be available as new innovations and products are introduced.

\subsection{Facilities and Institutional Resources}

The institution should have an active VHD surgical program with at least 2 institutionally based cardiac surgeons experienced in valvular surgery and should contain a full range of diagnostic imaging and therapeutic facilities, including:

1. A cardiac catheterization laboratory, hybrid catheterization laboratory, or hybrid OR/catheterization laboratory equipped with a fixed radiographic imaging system and flat-panel fluoroscopy, offering catheterization laboratory-quality imaging and hemodynamic capability.

2. Noninvasive imaging

a. An Intersocietal Accreditation Commission-accredited echocardiography laboratory and preferably Level 3trained and National Board of Echocardiography- certified echocardiographers, transthoracic and transesophageal echocardiography capabilities with sonographers and echocardiographers experienced in echocardiography for TAVR annular sizing and postimplant evaluation as well as intraprocedural monitoring, and access to 3-dimensional echocardiography.

b. Vascular laboratory (noninvasive) with vascular specialists capable of performing and interpreting vascular studies.

c. CT laboratory (with multidetector CT scanner with a dedicated TAVR algorithm) with CT technologists and specialists who can acquire and interpret cardiac CT studies.

Imaging programs that can aid in the selection of orthogonal views for imaging during positioning of the valve (eg, fusion imaging) are also desirable. Integration of echocardiographic images, particularly 3-dimensional capabilities, is helpful. The availability of multidetector CT or cardiac magnetic resonance is a significant advantage, particularly if image fusion, which will become more widely used in the future, is possible. ${ }^{15}$

3. Physical space-the implantation suite should have a sterile environment that meets OR standards. Furthermore, it should have sufficient space to accommodate the necessary equipment for uncomplicated implantations as well as any additional equipment that may be necessary in the event of complications. This includes space for anesthesiology, echocardiography, hemodynamic support, and cardiopulmonary bypass equipment and a surgical team. A specifically designed hybrid OR interventional suite is ideal; however, in the absence of such a facility, the interventional cardiac suite should have:

a. Circulating heating, ventilation, and air conditioning laminar flow diffusers (providing smooth, undisturbed air flow, usually placed directly over the procedure table) that meet air exchange requirements for operating rooms

b. Asymmetrical/symmetrical 6-lamp $2 \times 4$ troffers (the inverted, usually metal trough suspended from the ceiling as a fixture to provide adequate high-output lighting for surgical intervention)

c. Enough power receptacles that meet surgical equipment requirements (The receptacles should have generator back-up in case of power failure.)

d. Capability of running cardiopulmonary bypass and other support equipment (eg, intra-aortic balloon counterpulsation, Impella, Tandem, extracorporeal membrane oxygenation) in the interventional suite

e. Gas outlets for the anesthesia machine and cardiopulmonary bypass machine

f. Minimum room size of 800 square feet $\left(74.3 \mathrm{~m}^{2}\right)$ to accommodate the standard equipment required in a 
cardiac catheterization laboratory (eg, high-definition displays and monitors, ultrasound machine for access, $\mathrm{O}_{2}$ analyzer and supply, defibrillator/resuscitation cart, suction, compressed air, CO-oximeter, activated clotting time analyzer) as well as echocardiographic equipment, sonographers, anesthesia equipment, emergency CT surgical team, and cardiopulmonary bypass equipment (eg, surgeon, assistant, scrub technicians, perfusionists), if needed

4. Interventional procedure supplies-the interventional suite should stock a large variety of supplies, including various access kits; endovascular sheaths and introducers ranging from 4- to 26-F in various lengths; a wide range of guidewires for various purposes; cardiac diagnostic and interventional catheters; vascular closure devices; balloon dilatation catheters ranging from 2 to $30 \mathrm{~mm}$ in diameter and of various lengths and profiles; bare-metal, drug-eluting, and covered stents (eg, coronary and peripheral); occlusive vascular devices and balloons; snares and other retrieval devices; drainage catheters; and various implantable device sizes with their delivery systems

5. Postprocedure recovery and intensive care facility with personnel experienced in managing patients who have undergone conventional open heart valve procedures, postprocedure recovery room for conscious-sedation patients with personnel experienced in caring for postcatheterization and balloon aortic valvuloplasty (BAV) patients

6. Use of a mobile $\mathrm{C}$-arm imaging system in an OR is not adequate or acceptable.

7. The 2012 ACCF/SCAI Expert Consensus Document on Cardiac Catheterization Laboratory Standards Update outlined the specifications for a hybrid catheterization laboratory/OR. ${ }^{22}$ Although a hybrid catheterization laboratory/OR is preferable, especially for alternativeaccess procedures, it is not a prerequisite if items $3 \mathrm{a}$ to $3 \mathrm{~g}$ are met.

Most importantly, the hospital should be dedicated to providing these services and support financially and without time constraints on the personnel involved. A special consideration is radiation safety training for all of the personnel involved in delivering TAVR. A dedicated administrator as a member of the team is necessary.

The complexity of TAVR and the magnitude of institutional resources required are similar to established heart transplant and cardiac assist device programs. An MDT is required, similar to the transplant and assist device programs. The concept of an MDT was endorsed by the CMS through the establishment of certification criteria for the use of heart transplantation and cardiac assist devices in centers and, moreover, for eligibility for reimbursement of services provided. The same regulatory system was applied to professionals providing these services. TAVR programs should undergo a similar regulatory process with CMS endorsement. Centers should be approved for TAVR programs if they have addressed the quality benchmarks in this document (See Section 7: Criteria for Establishing a TAVR Program and Maintenance of Competence) and the appropriate infrastructure and committed hospital support.

The institutional commitment required for a successful program goes beyond the space, personnel, and specialized facilities set forth in the previous text. The complex and time-consuming preprocedure patient triage process and the amount and intensity of postprocedure patient care after discharge are labor-intensive for physician and nursing staff, as are the informed consents and communications with patients, families, and referring providers.

Additionally, technological and administrative support for the medical, nursing, and technical personnel involved is required, preferably in a central setting. Ancillary testing facilities (eg, pulmonary function testing, echocardiography, vascular duplex scanning, clinical laboratory, and multidetector CT) should be of high quality and able to accommodate the patient volume in a timely fashion.

By their nature, these procedures should only be performed in institutions that routinely perform surgical aortic valve operations and participate in the STS National Database with outcomes that equal or exceed those expected for their case mix on the basis of national benchmarks. Similarly, only institutions with interventional cardiology programs that have established and successful programs endorsed by the National Quality Forum with percutaneous coronary intervention (PCI), BAV, catheter closure of periprosthetic valvular leaks, and insertion of septal closure devices with outcomes that equal or exceed those established nationally for similar procedures, should offer TAVR.

Long-term outcome reporting is obligatory, to track not only survival, but also other parameters, including periprocedural complications (eg, cerebrovascular accident, vascular, renal, infectious), aortic regurgitation, pacemaker needs, TAVR reintervention, TAVR structural valve failure, subsequent SAVR, and QoL. This reporting is essential because long-term outcome goals for these new procedures have not been established at this early stage. Participation in a national data registry or registries (eg, the STS/ACC TVT Registry, STS National Database, ACC National Cardiovascular Data Registry [NCDR]) is mandatory. ${ }^{13}$

\section{PROCESS PROGRAM REQUIREMENTS}

The measures of process quality in TAVR, defined as best practices and standardized processes that are accepted and incorporated into programs, are outlined in the 2017 ACC Expert Consensus Decision Pathway for Transcatheter Aortic Valve Replacement in the Management of Adults with Aortic Stenosis. ${ }^{15}$ Current process measures include the incorporation of the ACC/AATS/AHA/ASE/EACTS/ HVS/SCA/SCAI/SCCT/SCMR/STS 2017 Appropriate 
Use Criteria for the Treatment of Patients with Severe Aortic Stenosis, ${ }^{23}$ documentation of MDT-based decision making during patient selection, and procedure performance by a cardiologist and surgeon. Patients and families need to be involved in the process of SDM in relation to VHD. ${ }^{24}$ Best practices may include: (1) directing patients and families to an objective, noncommercial SDM tool designed by patients and clinicians, to provide knowledge regarding aortic valve disease and its treatment; and (2) access to decision aids that allow for assessment of patientspecific risk and benefit for both TAVR and SAVR ${ }^{25}$ Other best practices ${ }^{7}$ include offering patients access to their medical records and training clinicians to help patients define their goals and treatment preferences. SDM has been actively promoted by CMS to enhance beneficiary engagement and incentives. ${ }^{26}$

\subsection{Patient Selection Requirements}

TAVR is currently approved in the United States for patients with severe native aortic stenosis (AS) and an intermediate or higher predicted operative 30-day mortality risk for SAVR, as well as valve-in-valve (ViV) indication for degenerated aortic bioprosthetic valves in patients who are at high risk for reoperation. Patients with these categories of valve disease need a multidisciplinary approach for their evaluation. There should be documentation that each patient has been made aware of the techniques of implantation as well as the risks and benefits for both forms of AVR therapy, whether they are a candidate for treatment with TAVR, SAVR, or either form of therapy. The patient should be informed about both which therapies are available at their hospital and the MDT's recommendations to facilitate achieving the best outcomes given their specific characteristics, risk, and goals of care. The volume and outcomes of both TAVR and SAVR for the site should be discussed with the patient. This sets the stage for SDM with the key element of incorporating patient preferences. Patients presenting to SAVR-only institutions should also be evaluated by an MDT.

\subsubsection{MDT Patient Case Conference Requirements}

The discussion by the MDT should drive the recommended procedure. Accordingly, criteria related to both SAVR and TAVR are addressed in this document. For some patients in whom either therapy is not appropriate, medical or palliative therapy should be offered. Therefore, programs need to have resources and a process in place that meet the following requirements:

1. Patients are evaluated by the MDT, as detailed in Section 3.2, Multidisciplinary Team.

2. The MDT incorporates relevant professional management guidelines and appropriate use criteria (AUC) for all forms of care for AS, including TAVR, SAVR, medical therapy, and palliative care (BAV is considered 1 option for palliative care).
3. Patients are informed of the MDT's recommendations regarding treatment options.

4. The program incorporates best practices for educating patients and their families.

5. The program implements patient-family SDM, including patient preferences.

Establishing and maintaining a TAVR program requires several key components (Tables 1-3).

In the initial National Coverage Determination (NCD) for TAVR in 2013, one of the major requirements for programs was that "two cardiac surgeons have independently examined the patient face-to-face and evaluated the patient's suitability for open aortic valve replacement (AVR) surgery; and both surgeons have documented the rationale for their clinical judgment and the rationale is available to the heart team." 27

In the 2012 Multisociety (AATS, ACCF, SCAI, and STS) Expert Consensus Statement: Operator and Institutional Requirements for Transcatheter Valve Repair and Replacement, Part 1: Transcatheter Aortic Valve Replacement, this issue was addressed differently, as follows:

- "A cardiac surgeon and an interventional cardiologist must evaluate each case. Interplay between interventional cardiologists and cardiac surgeons represent only part of the benefit of the MDT."

- "Direct patient evaluation by cardiologists and cardiac surgeons may be accomplished jointly and, if possible, simultaneously in a venue such as a multidisciplinary valve program clinic."1

This 2018 update addresses the need for a multidisciplinary approach and the importance of patient access, when appropriate, to all treatment options, by requiring that the following be documented:

- One cardiac surgeon (rather than 2) at the TAVRperforming institution, who is part of the MDT, has independently examined the patient face-to-face; evaluated the patient's suitability for SAVR, TAVR, or medical or palliative therapy; and has documented the rationale for their clinical judgment. The rationale and recommendations must be available to the MDT. Documentation from 2 cardiac surgeons is no longer felt necessary because of the established role of TAVR with published $\mathrm{AUC}^{24}$ and greater experience in the assessment of risk for SAVR.

- There should also be documentation of an additional physician who has independently examined the patient face-to-face, evaluated the patient's suitability for all forms of valve therapy, and documented the rationale for their clinical judgment. That rationale must be available to the MDT.

- For patients having TAVR, this documentation is typically provided by an interventional cardiologist who 
is part of the TAVR program, although general cardiologists with an expertise in VHD can provide this documentation.

- For patients having SAVR, this documentation can be provided by a variety of physicians and preferably at least 1 physician from the MDT; however, the additional physician does not necessarily have to be part of the team as long as he or she is knowledgeable, is well-informed with regard to the current status of all forms of treatment for aortic valve disease, and has knowledge of TAVR. The purpose of this requirement is to emphasize the importance of patients being wellinformed regarding all treatment options according to their clinical circumstances.

- It is reaffirmed that this direct patient evaluation is optimally performed jointly in a multidisciplinary valve clinic.

- Documentation of a multidisciplinary approach by both a surgeon and another clinician with knowledge and experience with TAVR is especially necessary for patients for whom there is an FDA-approved device with a relevant indication for use. Presently this includes all patients with trileaflet, native AS who have an intermediate or higher assessed risk for SAVR and patients with a failed bioprosthesis in the aortic position who are assessed as high risk for SAVR or considered not to be an open operative candidate. For programs involved in trials of TAVR versus SAVR in low-risk or other patient groups, it is expected that this joint evaluation would be extended to these groups as well.

\subsubsection{Operational Details}

- The MDT should be codirected by an interventional cardiologist and a cardiac surgeon, both of whom are responsible for meeting programmatic quality metrics and credentialing, as outlined in Tables 1, 2, and 4. The MDT, however, goes well beyond this central collaboration and should include key providers from other physician groups (eg, noninvasive cardiology, palliative care, geriatrics, and critical care medicine) as well as advanced patient practitioners, nurses, research personnel, and administrators. Thus, the MDT must take into account the broad range of resources necessary for a successful multidisciplinary valve therapy program.

- Formal group MDT meetings (distinct from the usual "cardiac catheterization conference") should take place regularly to review all patients referred for procedures, consider patient selection, and discuss morbidity and mortality and long-term outcomes of treated patients. In addition, these formal meetings of the MDT should form the basis for a local "TAVR Steering Committee" that provides oversight and direction for the TAVR program.
- Following the decision that a given patient is an appropriate candidate for TAVR, the procedure must be carefully planned. Cardiac surgical teams are familiar with and routinely use "pre-procedure briefings" before complex cardiac surgical operations. In such briefings, immediately prior to the procedure, all team members (ie, surgeons, anesthesiologists, perfusionists, nurses, and technicians) discuss the intended procedure, including the following: (1) the steps of the planned procedure; (2) specific tools and equipment needed (beyond those typically used); (3) possible complications that may arise during the procedure; and (4) contingency plans that will be implemented should the unexpected occur. The immediate availability of MDT physician support in emergency decision making and therapy is essential. It is, therefore, important that the roles of the various specialties be clearly delineated during preprocedure planning.

- Complicated postprocedural courses are common in high-risk patients, who comprise a significant portion of the population treated with TAVR. A team approach in this setting is critical. Specific and regular in-service educational conferences to impart the necessary familiarity are recommended.

- Long-term follow-up for these patients is imperative. Long-term follow-up planning and resources for this important phase of care are incumbent responsibilities of the MDT and the hospital administration.

- Post-approval registries (eg, STS/ACC TVT Registry) ${ }^{28}$ are required for TAVR. Therefore, a data collection/ research unit and staff within the MDT are necessary components that should be funded by the hospital.

- A financial structure that shares physician reimbursement for these procedures is a recommended incentive for collaboration between cardiac surgeons and cardiologists. This important principle will ensure that cardiac surgeons and cardiologists participate jointly in performing procedures and that each patient receives optimal patient-centered treatment.

- It has been demonstrated that a dedicated full-time individual (such as an experienced advanced cardiac nurse specialist serving as clinical coordinator) can be supportive of the efficient operational function of the MDT.

\subsubsection{Patient Selection Considerations}

There are legitimate concerns that many patients with severe AS meeting the expanding indications for TAVR are not currently being provided critical information regarding their treatment options. There are 2 potential concerns associated with underutilization of TAVR. First, patients with symptomatic, severe AS, especially those deemed at excessive risk for SAVR, may not learn of the TAVR option. Second, some patients undergoing SAVR, especially those 
TABLE 3. Requirements for continued certification for existing TAVR programs

\section{Criteria}

Optimal program characteristics include documentation of multidisciplinary approach and patient access to all forms of therapy for aortic valve disease

(TAVR, SAVR, and medical therapy) using an SDM process.

- For all patients with aortic stenosis meeting criteria for valve replacement, there should be documentation of the following:

- An evaluation completed by both a cardiac surgeon and cardiologist with knowledge and experience in both TAVR and SAVR;

○ Education of patients regarding the treatment recommendations and options;

- The use of an SDM process incorporating patient preference.

- For patients undergoing TAVR, there should be documentation of an evaluation by 1 surgeon involved in the TAVR program.

- For this requirement to meet CMS coverage criteria, the NCD recommendation of evaluation by 2 surgeons for all patients having TAVR should be updated.

TAVR Volume and Quality Requirements

To have optimal outcomes, a program will have:

- $\geq 50$ cases per year or 100 cases over 2 years

- Minimum quality requirement: STS/ACC TVT Registry-reported 30-day risk-adjusted all-cause TAVR mortality above the bottom 10\% for metrics outlined in Table 1.

To have optimal outcomes, a program will ensure program directors are responsible for accurately reporting MDT clinical volume and outcomes to the STS/TVT Registry and the STS National Database.

To have optimal outcomes an institution will have the following resources and experience:

- PCI

$\circ \geq 300$ PCIs/year

- Active participation in the NCDR/Cath PCI Registry or a validated state/multi-institutional consortium that gathers and reports risk-adjusted and benchmarked outcomes

○ PCI in-hospital risk-adjusted mortality (NQF endorsed) above the bottom 25 th percentile for 4 consecutive quarters.

- Vascular interventions*

- Experienced and competent physicians in vascular arterial interventions

- Pacemaker capabilities

- Experienced and competent physicians for temporary and permanent pacemaker placement and management.

○ On-site services available $24 \mathrm{~h} /$ day and 7 days/week to handle conduction disturbances as a result of TAVR

SAVR Volume and Quality Requirements

To have optimal outcomes a program will have:

- $\geq 2$ hospital-based cardiac surgeons who both spend $\geq 50 \%$ of their time at the hospital with the proposed TAVR program

- $\geq 30$ SAVRs per prior year or 60 over 2 years $\dagger$

- Quality assessment/quality improvement program:

- Active participation in STS National Database to monitor outcomes

○ Quality Metric: STS 2 or 3 star rating for isolated AVR and AVR + CABG in both reporting periods during the most recent reporting year

To have optimal outcomes, a program will have a quality assessment/quality improvement program that includes:

- Active institutional participation in the STS/ACC TVT Registry and STS National Database or a validated state/multi-institutional consortium registry

- Registry submission of all commercial cases using FDA-approved TAVR/SAVR technology, including off-label uses.

O Registry documentation that data submissions meet performance metrics for completeness and accuracy as defined by each registry

- MDT quarterly meetings, with documentation of the following:

- Review of institutional reports for TAVR (quarterly) and SAVR (semiannually) from the STS/ACC TVT Registry or STS National Database or an alternative approved registry

- Assessment and proposed actions if site performance for TAVR and SAVR is suboptimal relative to volume and quality requirements, including national benchmarking of performance metrics as outlined in Tables 1 and 2

o Presentation of selected TAVR/SAVR cases at quarterly mortality/morbidity conferences.

- Documentation of incorporation of TAVR/SAVR AUC in the patient selection process ${ }^{2}$

To have optimal outcomes, all MDT members will participate in appropriate CME annually.

$T A V R$, Transcatheter aortic valve replacement; $A A V R$, surgical aortic valve replacement; $C M S$, Centers for Medicare \& Medicaid Services; NCD, National Coverage Decision; STS, Society of Thoracic Surgeons; ACC, American College of Cardiology; TVT, Transcatheter Valve Therapies; PCI, percutaneous coronary intervention; NCDR, National Cardiovascular Data Registry; FDA, U.S. Food and Drug Administration; $A U C$, appropriate use criteria; $C M E$, continuing medical education. *Vascular arterial interventions include TEVAR/EVAR, carotid stenting, renal artery stenting, iliac and femoral artery stenting, coarctation stenting, and acute limb ischemia-related interventions. $\nmid$ For the purposes of this hospital volume requirement SAVR is defined to include all aortic valve replacement (mechanical, bioprosthesis, homograft, autograft [Ross], composite valve graft or root replacement) or aortic valve repair procedures, including concomitant valve resuspension for acute aortic dissection and valve-sparing aortic root replacement. Simple adjuvant aortic valve procedures (eg, suturing closed regurgitant aortic valves in an LVAD patient, excising a papillary fibroelastoma or thrombus, and so on) are not counted. 
TABLE 4. Requirements for new TAVR programs

\section{Criteria}

There should be documentation of a multidisciplinary approach and of patient access to all forms of therapy for aortic valve disease (TAVR, SAVR, and palliative and medical care using an SDM process.

- For all patients with aortic stenosis meeting criteria for valve replacement, there should be documentation of the following:

- Completion of an evaluation by both a cardiac surgeon and a cardiologist with knowledge and experience in both TAVR and SAVR

- Education of patients regarding the treatment recommendations and options by the multidisciplinary team

- Use of an SDM process incorporating patient preference

- For patients undergoing TAVR, there should be documentation of evaluation by 1 surgeon involved in the TAVR program.

- For this requirement to fulfill CMS coverage criteria, the NCD should be updated as it currently recommends evaluation by 2 surgeons for all patients having TAVR.

The proposed TAVR proceduralist for a new TAVR program should document the following:

- Prior TAVR experience with participation in 100 transfemoral TAVRs lifetime, including 50 TAVRs as primary operator

- Being board eligible or certified in either interventional cardiology or cardiothoracic surgery

- Certification of device-specific training on device(s) to be used.

The TAVR sites must have:

- The site must have documented expertise, state of the art technology, and a dedicated board-certified imager that is a member of the MDT.

- Echocardiography: TTE, TEE, and 3-dimensional

- CT scan and MR imaging

The proposed TAVR surgeon for a new TAVR program should document the following:

- 100 lifetime SAVRs, 25 per prior year, or 50 over 2 years and $\geq 20$ SAVRs in the year prior to TAVR program initiation. Board eligible or certified by the American Board of Thoracic Surgery or equivalent.

The institution should document the following prior to expanding into alternative-access TAVR (eg, transapical, direct aortic, brachiocephalic arteries, transcaval):

- Completion of 80 TAVRs using transfemoral access with an STS/ACC TVT Registry 30-day risk-adjusted TAVR all-cause mortality "as expected" or "better than expected"

The institution should document the following concerning its SAVR program:

- $\geq 2$ hospital-based cardiac surgeons who both spend $\geq 50 \%$ time at the hospital with the proposed TAVR program

- Minimum hospital SAVR volume*: 40 per prior year or 80 over 2 years

- Quality assessment/quality improvement program:

- Active participation in the STS National Database or a validated state/multi-institutional consortium that gathers and reports risk-adjusted and benchmarked outcomes $\dagger$

- Quality metric: STS 2- or 3-star rating for isolated AVR and AVR plus CABG in both reporting periods during the most recent reporting year

The institution should document the following resources and experience:

- PCI

- Minimum volume: $300 \mathrm{PCI} / \mathrm{year}$

- Active participation in the NCDR/Cath PCI Registry or a validated state/multi-institutional consortium that gathers and reports risk-adjusted and benchmarked outcomes

- Quality metric: PCI in-hospital risk-adjusted mortality (NQF endorsed) above the bottom 25th percentile for the most recent 4 consecutive quarters.

- Vascular interventions

○ Physicians experienced and competent in vascular arterial interventions $\ddagger$

- Pacemaker capabilities

$\circ$ Experienced and competent physicians for temporary and permanent pacemaker placement and management

- On-site services should be available $24 \mathrm{~h} / \mathrm{day}$ and 7 days/week to handle conduction disturbances as a result of TAVR

Program directors are responsible for accurate reporting of multidisciplinary team clinical volume and outcomes to the STS/TVT Registry and the STS National Database. $\dagger$

Quality assessment/quality improvement program requirements:

- Active participation of institution in STS/ACC TVT Registry and STS National Database or a validated state/multi-institutional consortium registry $\dagger$

○ Registry submission of all cases using FDA-approved TAVR/SAVR technology, including off-label uses $\S$

- Registry documentation that data submissions meet performance metrics for completeness and accuracy as defined by each registry

- Multidisciplinary team quarterly meetings with documentation of the following:

○ Review of institutional reports for TAVR (quarterly) and SAVR (semiannually) from the STS/ACC TVT Registry and STS National Database or an alternative approved registry 
○ Assessment and proposed actions if site performance for TAVR and SAVR is suboptimal relative to volume and quality requirements, including national benchmarking of performance metrics as outlined in Tables 1 and 2

- Presentation of selected TAVR/SAVR cases at quarterly mortality/morbidity conferences

Documentation of incorporation of TAVR/SAVR AUC into patient selection process ${ }^{23}$

Continuing education requirements:

- It is expected that the MDT will participate in appropriate CME.

$T A V R$, Transcatheter aortic valve replacement; $S A V R$, surgical aortic valve replacement; $C M S$, Centers for Medicare \& Medicaid Services; $N C D$, National Coverage Decision; $C T$, computed tomography; $M R$, magnetic resonance; STS, Society of Thoracic Surgeons; $A C C$, American College of Cardiology; TVT, transcatheter valve therapies; $P C I$, percutaneous coronary intervention; NCDR, National Cardiovascular Data Registry; $N Q F$, National Quality Forum; FDA, U.S. Food and Drug Administration; AUC, appropriate use criteria; $C M E$, continuing medical education. *For the purposes of this document, the hospital volume requirement for SAVR is defined to include all aortic valve replacement (mechanical, bioprosthesis, homograft, autograft [Ross], composite valve graft, or root replacement) or aortic valve repair procedures, including concomitant valve resuspension for acute aortic dissection and valve-sparing aortic root replacement. Simple adjuvant aortic valve procedures (eg, suturing closed regurgitant aortic valves in an LVAD patient, excising a papillary fibroelastoma or thrombus, and so on) are not counted. †Or analogous if only reporting to other state or national database. $\ddagger$ Vascular arterial interventions include TEVAR/EVAR, carotid stenting, renal artery stenting, iliac and femoral artery stenting, coarctation stenting, and acute limb ischemia-related interventions. $§$ Does not include patients in ongoing clinical trials.

being seen at hospitals only offering SAVR, may not be informed when TAVR is an appropriate option.

The MDT approach provides patients and families with a comprehensive evaluation and determination as to whether TAVR, SAVR, or both are appropriate options for patients. It is unclear to what extent patients who are evaluated by physicians and hospitals without TAVR programs are being informed of their potential eligibility for TAVR. It is important to understand that there are over 500 programs in the United States that only offer SAVR. The requirements for patient education and SDM outlined in this document are directed toward programs that offer TAVR and/or SAVR.

\subsubsection{Frailty, Cognition, QoL, Immobility, and Disability}

Arnold et al, ${ }^{29}$ using PARTNER (Placement of Aortic Transcatheter Valve) Trial TAVR patients, were the first to compile an analytic risk predictor based on the KCCQ. Poor outcome was defined as death, KCCQ $<45$, or decrease in KCCQ $\geq 10$. Thirty-five percent of patients had a poor outcome at 6 months $(19 \%$ dead, 16\% alive without functional benefit). ${ }^{29}$ Looking at 1-year outcomes after TAVR in 3 PARTNER sites at which frailty was rigorously assessed, this group used a KCCQ threshold of $<60$ to predict poor outcome. ${ }^{30}$ The frail patients had a 33\% mortality rate, compared with $16 \%$ for those who were not deemed frail $(P=.004)$. Poor outcome occurred in $50 \%$ of the frail subgroup versus $32 \%$ of the nonfrail subgroup $(P=.02) .{ }^{31}$ When the 2011 to 2014 STS/ACC TVT Registry cohort was analyzed using baseline and 1-year KCCQ, those who initially self-reported very poor health status (KCCQ <25) had a 1-year mortality exceeding $25 \%$ after TAVR-more than twice as high as those who felt they had "good" health status at baseline. ${ }^{32}$ Puls et al. observed that frailty, as assessed by the simple Katz index of daily living activities, had a major influence on TAVR outcome in a German single-center study. ${ }^{33}$ Adjusted for all other variables, patients with a Katz score $<6$ had a $47 \%$ mortality rate at 2 years, compared with $26 \%$ for those with a Katz index of 6 , with an intermediate outcome for those with a Katz index of 3 to 5 . Approximately $50 \%$ of patients with a Katz index $\leq 2$ were dead by 2 years postTAVR. $^{29}$

Aside from identifying patient characteristics that portend prohibitively high mortality rates over the first few years after TAVR, an equally important consideration is avoiding TAVR in patients who realistically will not gain any functional benefit or have better QoL after TAVR, or may even experience functional decline due to age and/or a constellation of comorbidities. Once a suitable risk algorithm that identifies such individuals is developed and validated, the task of selecting patients for whom procedural denial is appropriate will be clearer. ${ }^{34}$ Schoenenberger et $\mathrm{al}^{35}$ found that $21 \%$ of 106 surviving TAVR patients had experienced functional decline at 6 months. They demonstrated that a multidisciplinary frailty index (cognition, mobility, nutrition, activities of daily living) strongly predicted functional decline, even when adjusted for STS and EuroSCORE. Such measures should be incorporated into the TAVR triage process, along with active gerontology and palliative care representation on the MDT, to avoid performing TAVR in patients who are not going to benefit from the procedure. $^{34}$ In current practice, BAV is sometimes used to assess the patients' clinical response to relief of AS. Patients with no clinical improvement after successful BAV should not be considered candidates for TAVR.

\subsubsection{Procedural Denial, Futility, QoL, and Limited Life Expectancy}

The evolution of TAVR in the United States started with extreme-risk patients before encompassing high- and intermediate-risk patients. At present, 2 trials are randomizing low-risk patients to SAVR or TAVR. As indications for TAVR expand into lower-risk populations, the longterm outcomes of TAVR have become a major consideration, because in contrast to that of surgically implanted 
valves, the durability of bioprosthetic TAVR valves is unknown. Even though ViV options are available for patients considered to be at high or prohibitive risk for redoSAVR, the procedure can lead to an undersized valve for the patient (prosthesis/patient mismatch).

An ongoing challenge is the selection of patients most likely to benefit from TAVR who are either inoperable or at prohibitive risk for surgery. Coexistent diseases, such as end-stage renal disease, recent stroke, untreated coronary artery disease, severe chronic obstructive pulmonary disease, severe pulmonary hypertension, severe mitral regurgitation, active neoplasms, and endocarditis, were exclusion criteria in the controlled trials; thus, a substantial minority of patients (so-called Cohort C patients) were not included. Other factors, such as frailty and liver disease, were not incorporated into the overall risk assessment process in the early trials. Even though these sicker patients were excluded, the all-cause 5-year mortality rates of patients who received TAVR in the PARTNER 1B and PARTNER 1A trials were $72 \%{ }^{36}$ and $68 \%,{ }^{37}$ respectively.

Attention has recently been focused on the use of metrics that can identify patient and procedure characteristics that are predictors of optimal, suboptimal, or bad outcomes, both early and at 1-year follow up. Survival rates, or conversely mortality rates, are inadequate by themselves. Other outcomes that have been studied include patientreported health status (KCCQ), rehospitalization rates, and objective measures of functionality. These outcomes are best understood when they are compared before and after TAVR.

From these initial reports it is reasonable to conclude the following:

- TAVR is not appropriate for patients who have reached a level of futility (life expectancy despite TAVR of $<1$ year). ${ }^{38}$

- TAVR is not appropriate as an end-of-life treatment as it does not help patients and is not sustainable financially for society.

- Real-world application of TAVR is not constrained by the strict exclusion criteria inherent in the controlled trials; thus, sites need to carefully assess their selection criteria and subsequent TAVR outcomes.

- The benefit of TAVR should be defined not only by survival compared with alternative management strategies but also in terms of patient-reported health status, including QoL, freedom from recurrent hospitalization, maintenance of independent living, and functional state at 1 year.

- Procedural denial in elderly patients with multiple medical problems and limited life expectancy should not be misconstrued as a personal defeat. ${ }^{39}$

- Initial reports studying changes in KCCQ score are useful for defining the impact of TAVR on patient-reported health status. $\circ$ The score is not disease specific and is influenced by other conditions that are often present in elderly patients with severe AS.

- These reports included predominantly inoperable and high-risk patients and are not likely to reflect the benefits of TAVR in intermediate-risk patients.

- TAVR procedure and 1-year outcomes have overall improved since these analyses were completed; therefore, these studies need to be updated for contemporary patients undergoing TAVR, as well as SAVR.

- We currently do not have predictive tools that can clearly differentiate between those who will benefit from TAVR and those who will not. It is naïve to expect that predictive "crystal balls" will ever remove uncertainty regarding the outcome of an individual patient, but these tools do allow some empirical evidence to be incorporated into the SDM process:

- Arnold et al. ${ }^{40}$ have developed outcome predictive models that need to be used prospectively and validated.

- The thresholds of an acceptable probability of optimal, suboptimal, and poor outcome are somewhat arbitrary.

- Theoretically, determining that a patient is likely to derive no benefit from TAVR is 1 justification for procedural denial; this information should be provided to patients and their families so that they can exercise individual autonomy. Furthermore, physicians must be responsible stewards of society's limited resources. ${ }^{30,31,34,41-45}$

- Procedural denial based on imperfect predicative models and clinical judgment does involve an ethical challenge for clinicians.

- Decision making in patients who may have reduced benefit from TAVR does not necessarily mandate that the MDT team deny treatment; however, it should initiate a more thoughtful discussion with the patient and family before moving forward with TAVR. Utilization of palliative care consultants is helpful.

- Progress has been made in identifying patient characteristics that are statistically associated with markedly limited life expectancy and lower likelihood of functional benefit after TAVR. ${ }^{45}$ No single one of these factors clearly supports denial of TAVR as an option, but they inform the decision process and discussion with the patient and family.

- These characteristics include end-stage renal disease or dialysis, ${ }^{46-50}$ advanced lung disease (especially if oxygen dependent), ${ }^{51,52}$ slow ambulation (6-min walk time $<150$ m), ${ }^{51}$ atrial fibrillation, ${ }^{46}$ poor LV systolic function (LV ejection fraction $<30 \%$, LV stroke volume index $\leq 35$ $\mathrm{mL} / \mathrm{m}^{2}$, impaired contractile reserve with dobutamine stress echocardiography), ${ }^{53}$ low aortic gradient, ${ }^{53}$ 
pulmonary hypertension, ${ }^{43,52}$ severe organic mitral regurgitation, ${ }^{54}$ and STS-Predicted Risk of Mortality (PROM) score $>15 \% .{ }^{36}$ Advanced dementia and impaired cognitive ability, active cancer, marked musculoskeletal disability, debilitating frailty, and severe cachexia and sarcopenia (low body mass index) are other obvious conditions for which TAVR procedural denial may be appropriate.

\subsubsection{Predictive Risk Models}

SDM has also been actively promoted by the professional society guidelines on the management of VHD, incorporating both the MDT approach and the assessment of individualized patient risk that is available for both SAVR and TAVR. The following are recognized risk calculators for each procedure:

- Online STS Adult Cardiac Surgery Risk Calculator

- The STS/ACC TAVR In-Hospital Mortality Risk App available for download

Comparing results from the STS calculator with those of the TAVR calculator for an individual patient does not offer equivalent information, as the data utilized to create each of these calculators come from a different source. Even though the STS surgery risk calculator was developed using early (30-day) death after open SAVR as the dependent variable, it was convenient to use this risk score for patient selection in the early controlled TAVR trials. In the PARTNER 1B trial, despite an overall approximately $20 \%$ improvement in late survival rate compared with standard medical therapy, patients with an STS-PROM score over $15 \%$ who received TAVR did not have any appreciable benefit in all-cause mortality out to 5 years $(P=.075){ }^{36}$ It was only with respect to cardiovascular death at 5 years that patients with an STS-PROM score $>15 \%$ who received TAVR lived significantly longer $(P=.01)$ than did those who received medical therapy. ${ }^{36}$ Therefore, when the STSPROM score exceeds $15 \%$, it is valuable in deciding whether or not TAVR is futile and should be withheld.

\subsection{SDM Requirements}

It should be the goal of each TAVR program that patients participate meaningfully in their healthcare decisions. To this end, patients should: (1) be well-informed regarding their options; (2) understand the risks and benefits presented using data on treatment options that are as patient-specific as possible; (3) articulate their treatment- and recovery-related goals; (4) identify preferences and values relative to their care; and (5) integrate these to make a final treatment choice.

The CMS has actively promoted this SDM process to enhance beneficiary engagement and incentives in an SDM model:

The Centers for Medicare \& Medicaid Services (CMS) identifies strengthening beneficiary engagement as one of the agency's goals to help transform our health care system into one that delivers better care, smarter spending, healthier people, and puts individuals at the center. Specifically, the CMS Quality Strategy envisions health and care that is person-centered, provides incentives for the right outcomes, is sustainable, emphasizes coordinated care and SDM, and relies on transparency of quality and cost information. ${ }^{26}$

In the 2017 AHA/ACC Guidelines for the Management of Patients With Valvular Heart Disease, the decision-making process was firmly placed into professional recommendations with a Class I, Level of Evidence: C-LD: "The choice of type of prosthetic heart valve should be an SDM process that accounts for the patient's values and preferences and includes discussion of the indications for and risks of anticoagulant therapy and the potential need for and risk associated with reintervention." ${ }^{55}$ [This quote has been modified to add emphasis on the SDM process.]

The achievement of the goals of SDM can be challenging and time-consuming. As pointed out by CMS, "practitioners have found it difficult to integrate SDM into their routine workflows for various reasons such as overworked physicians, insufficient practitioner training, inadequate clinical information systems, lack of consistent methods to measure that SDM is taking place, and uncertainty as to whether, or how, to promote change and invest in the time, tools, and training required to achieve meaningful SDM.",26

Specific to the issue of SDM in TAVR and SAVR, several ongoing efforts to develop decision aids will be available to TAVR sites later in 2018. These aids will provide clinicians, patients, and families with tools that will help institutions and patients exhibit the 5 features of meaningful patient participation in their healthcare decisions listed in the previous text. The 2 efforts are:

1. A Patient-Centered Outcomes Research Institutesponsored project directed out of the Duke Clinical Research Institute that features a web-based resource for patient education regarding TAVR and SAVR, plus a patient-specific assessment of the risks of TAVR and SAVR using quality measures from the STS/ACC TVT Registry. ${ }^{25}$

2. An ACC CardioSmart-sponsored initiative directed out of the University of Colorado that features 2 paper decision aids and web-based videos that address patients at moderate SAVR risk who are making a choice between TAVR and SAVR, ${ }^{56}$ and patients considered inoperable who are making a choice between TAVR and medical management. ${ }^{57}$

\section{OUTCOME REQUIREMENTS}

The outcome measures of quality and associated requirements are outlined in the accompanying tables. Tables 3 
and 4 include outcome measures of quality for PCI and SAVR. Table 1 includes outcome measures of quality for TAVR, which are the beginning of an evolution that can eventually bring TAVR measures close to the maturity, validation, and sophistication of current SAVR measures.

The principal outcome measure for isolated SAVR from the STS National Database is a composite score that comprises: (1) risk-adjusted operative mortality (death occurring during the index hospitalization or following transfer to another acute care facility, or death within 30 days of surgery); and (2) the risk-adjusted occurrence of any of the following 5 major complications - renal failure, stroke, cardiac reoperation, sternal infection/mediastinitis, or prolonged ventilation. ${ }^{58}$ This measure relates to the fundamental goal of SAVR and TAVR: increasing the likelihood of survival, full functionality, and improved QoL. This measure of SAVR outcomes enables differentiation of site performance, with the subsequent assignment of a star rating to each site.

Outcomes measures for TAVR should also address the goals of care for predominately elderly and frail patients with numerous comorbidities, with TAVR approval now extended for intermediate-, high-, and extreme-risk patients. These features of TAVR patients highlight the need to objectively assess whether TAVR improves functional state and QoL at 1 year as well as the need to adjust TAVR outcomes measures for diverse patient characteristics. In the future, SAVR will also need to include assessments of 1-year outcomes, including patient-reported health status with its QoL component.

The STS/ACC TVT Registry has incorporated patientreported health status using the KCCQ, which has been validated in AS. ${ }^{59}$ The derived patient score gives valuable information regarding the patient's status both pre- and postTAVR. The baseline score is useful as a prognosis marker, and the change in KCCQ post-TAVR is a marker of whether the patient has derived benefit. ${ }^{32,60}$ Rehospitalization rates are additional measures of outcomes that can be considered to assess broad aspects of care, including patient selection, procedure performance, and postprocedure care. Table 2 incorporates some of these measures as future metrics for sites to assess their performance.

Risk adjustment for 1 TAVR outcome-in-hospital mortality - has been developed, validated, and reported quarterly by the STS/ACC TVT Registry. ${ }^{61}$ A 30-day risk-adjusted algorithm has been developed and tested with implementation likely in 2018. Additional efforts to risk-adjust other major outcomes are underway. A composite outcome that includes multiple morbidities post-TAVR with risk-adjustment-similar to what is currently used for SAVR-is a future goal for assessment of TAVR outcomes. Challenges in reporting outcome measures and statistical approaches to addressing these challenges are discussed in Appendix 1.
All data used to fulfill the requirements to maintain a safe, efficient, and effective TAVR program are currently generated from the STS/ACC TVT Registry for TAVR and STS National Database for SAVR. These requirements will maintain uniformity, consistency, and quality control for all sites. Individual TAVR site reports are generated quarterly by the STS/ACC TVT Registry. Each metric is accompanied by a national benchmark with a median value and interquartile range analyzed from the previous rolling 4 quarters of all site data submitted to the registry that pass a data quality check. These national benchmarks are presented graphically using box plots (see Figure 3 ). As shown in Tables 1 and 2, this method of individual site data presentation is a convenient first step for programs to use as they assess their performance; however, the method has important limitations. Box and whisker plots only include a site's point estimate and do not provide a measure of the substantial uncertainty associated with small sample sizes. We therefore advocate the use of a widely employed alternative, the funnel plot, as described by Spiegelhalter. ${ }^{62,63}$ This graphical approach has numerous advantages. It explicitly conveys the greater random fluctuation inherent to samples drawn from programs with lower volumes, and can be used with varying upper and lower control limits (eg, $95 \%$ for outlier status, $90 \%$ for warning status). The STS database reports are based on 3 years of data and advance every 6 months.

Table 1 shows the current and future primary (ie, essential) performance metrics necessary for maintenance of both TAVR and SAVR programs. These metrics were chosen by consensus of expert opinion. One-year risk-adjusted mortality rate, composite measures, and patient-reported health status (including QoL, which is part of the KCCQ questionnaire) will be future outcomes metrics to be introduced into the maintenance requirements as the capabilities of the registry. In 2017, the STS/ACC TVT Registry started requiring a KCCQ metric comparing baseline and postTAVR scores.

Some warning signals for problematic performance are shown in Table 1 and include sites with worse than expected performance for risk-adjusted measures for 2 consecutive reports, and points falling outside the selected control limits on funnel plots for unadjusted measures. These findings mandate immediate attention to verify and remediate any quality issues. The TAVR center should strongly consider seeking outside review of their 1-year performance goals, including evaluation of their TAVR selection process and quality of care in the context of the challenges inherent in caring for a patient population that is often elderly and burdened by numerous comorbid conditions. There is broad agreement that excessive 1-year mortality and a low percentage of patients reporting improvement would comprise a red flag for a program to reconsider their approach and 
outcomes. For instance, pertinent questions include: (1) Is the program performing TAVR in many patients who may be at the futility stage of their condition? and (2) Is the program having problems with substandard procedure performance and postprocedure care? At the other extreme would be a program that has very low 1-year mortality and a high percentage of patients with higher than average KCCQ scores. This scenario raises other relevant questions. For example: (1) Is the program denying treatment to some high-risk patients who might benefit? (2) Does the program transfer more complex patients needing alternative access to another site? (This may be appropriate.) (3) Are many patients undergoing TAVR at this institution within a lowerrisk category than national benchmarks, outside of the AUC recently developed for patients with severe $\mathrm{AS}^{23}$ and outside of current FDA indications for use?

Table 2 is a continuation roadmap for site MDT quality assessment/quality outcomes conferences to regularly review each outcome metric in Tables 1 and 2, using nationally benchmarked data, and have their data available, when appropriate, for internal and external review. Table 2 also includes other secondary outcome metrics that should be monitored, evaluated, discussed, and compared with TVT registry-generated benchmarks to enhance the overall performance of a site program.

There are 2 important considerations in the use of Tables 1 and 2 for a site's quality assessment program. First, benchmarks should be continually updated given the substantial improvements in TAVR outcomes over the past 5 years. The quarterly report of the STS/ACC TVT Registry automatically updates these benchmarks on the basis of the last 4 quarters of reported data from sites meeting data quality standards. Second, the case mix for a TAVR center may change over time and may or may not be similar to the national average case mix of patients being treated at all centers. Presently, only in-hospital and 30-day mortality outcomes are risk-adjusted. Therefore, other outcomes are not risk-adjusted and need to be interpreted in the context of a program's constellation of patients and the spectrum of characteristics that impact outcomes. In the quarterly STS/ACC TVT Registry report, sites can see a breakdown of their heart team's assessment of the number and percentage of patients in the categories of extreme/prohibitive, high, intermediate, and low risk, with corresponding national statistics for the percentage of patients in each risk category.

\section{REGISTRY REQUIREMENTS}

Measurement of a participating site's quality of care is routinely presented to that site by the quarterly reports in benchmarked format from the STS/ACC TVT Registry. ${ }^{64}$ Sites receive reports on the quality and completeness of their data submission that determine if the submission is included in national benchmarks (Figure 4). The quarterly reports include the site's data for the last 4 quarters with key metrics presented relative to national benchmark descriptive statistics (Figure 3), although as noted previously, these box and whisker plots do not account for random statistical sampling error, especially from lowvolume programs (ie, there are no confidence intervals provided).

A central feature of this document is the need for physicians, hospitals, and other members of the MDT at the local level, in conjunction with professional societies at the national level, to develop and implement a scientifically rigorous approach for quality measurements of TAVR. The NCDR has extensive experience with the use of clinical registries to gather, analyze, and generate reports for sites to assess and improve the quality of care at their site. The STS also has extensive knowledge and experience with quality assessment specifically for SAVR. Using the past experience of both of these societies, a similar approach for TAVR will be outlined. ${ }^{58,65}$ The STS uses quality measures to provide members of their national database with a 1- to 3star rating system: 3 stars indicate highest performance, whereas 1 star indicates lowest performance in SAVR. ${ }^{58,65}$ Centers providing TAVR, as a rapidly evolving therapy, should focus on the use of quality measures for individual site and national quality improvement activities and also for performance assessment, public reporting, and documentation for pay-for-performance.

TAVR is still dynamic and rapidly evolving. Major clinical research issues remain unanswered. Some of the critical unanswered questions for TAVR in 2018 are listed in Table 5. Submission of data on all commercial TAVR cases to a national registry approved by CMS is an NCD requirement for all TAVR technologies. ${ }^{27}$ The STS/ACC TVT Registry (NCT01737528) has been approved by CMS to meet the registry requirements outlined in the NCD for TAVR. ${ }^{28}$ This process of ongoing evidence development is a CMS responsibility and is likely to continue as such for additional years.

The STS/ACC TVT Registry goes beyond the focus of clinical registries to monitor real-world outcomes of a procedure. The STS/ACC TVT Registry data are provided to industry, FDA, and CMS partners for post-approval studies, device safety surveillance, coverage with evidence development, and expansion of indications. ${ }^{66}$

Two major sources have provided the research infrastructure for learning about TAVR: industry-sponsored investigational device exemption pivotal randomized trials and clinical registries sponsored by professional societies. The gathering of real-world data on TAVR in the United States has been a primary function of the STS/ACC TVT Registry since 2012. The STS National Database has gathered data on SAVR since $1989 .{ }^{67}$ These clinical registries work with major analytic centers and, in the case of TAVR and SAVR, the Duke Clinical Research Institute houses the 


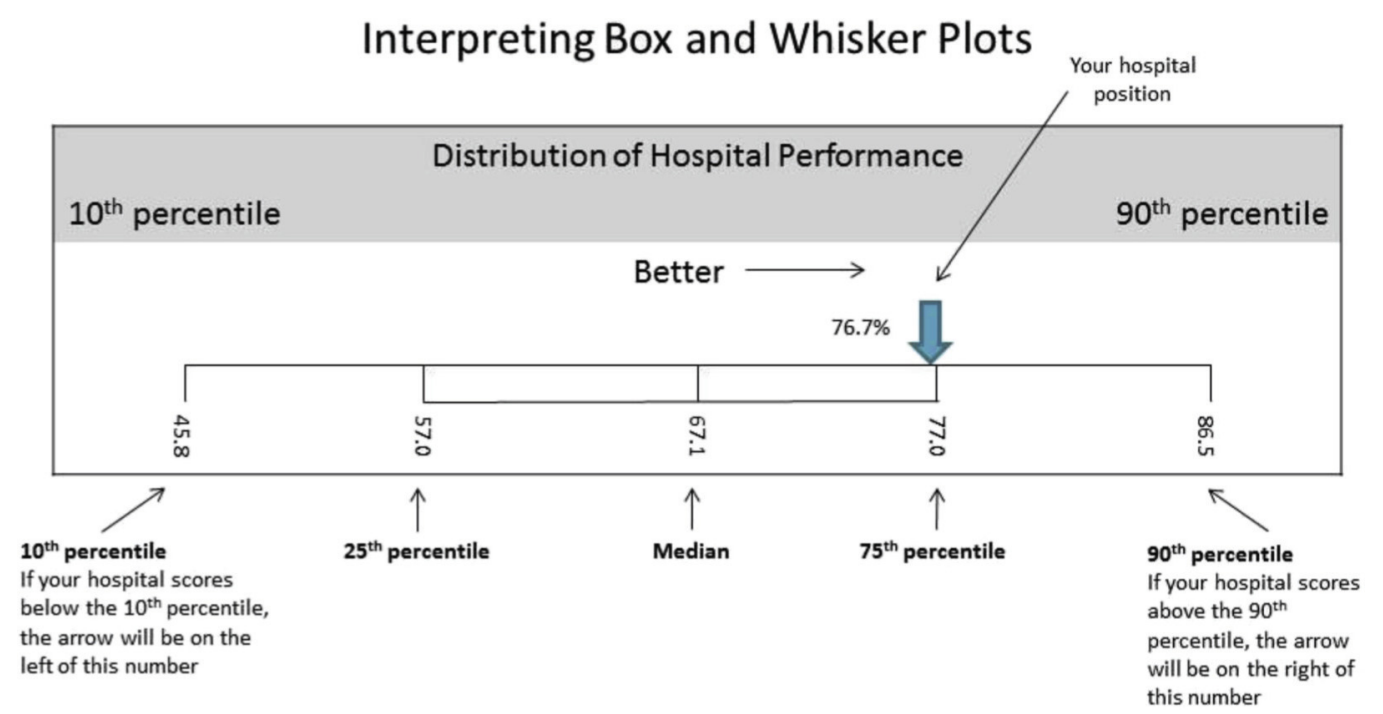

FIGURE 3. STS/ACC TVT registry example of a quarterly report to sites providing site performance in the context of national benchmark statistics. 10th Percentile- $90 \%$ of hospitals achieved "better" scores than the 10th percentile. 25th Percentile or 1st Quartile-75\% of hospitals achieved "better" scores than the 25th percentile. 50th Percentile or 2nd Quartile-Middle of the distribution: half of the hospitals' data are above and half are below the median. 75th Percentile or 3rd Quartile-25\% of hospitals achieved "better" scores than the 75th percentile. 90th Percentile-10\% of hospitals achieved "better" scores than the 90th percentile. Your hospital position- "Your Hospital Position" is in relation to all other hospitals' data.

data and performs analyses. Most recently, investigation is underway for other analytic centers to share in certain analyses and to include 1-year outcomes after SAVR. ${ }^{28}$

The STS/ACC TVT Registry and the STS National Database have robust research and publication processes. Since the inception of the STS/ACC TVT Research and Publications Committee, more than 200 proposals have been reviewed and more than 65 have been approved for analysis. ${ }^{68}$ Any registry participant and other qualified institution can submit proposals. Periodically, the Steering Committee of the STS/ACC TVT Registry takes the lead on research projects that are felt to be of high strategic importance. The list of publications and active research studies continues to grow and can be viewed on the STS/ ACC TVT Registry Web site. ${ }^{68}$ The STS/ACC TVT Registry Steering Committee publishes an annual report that distributes information regarding patient characteristics, processes of care, procedure details, and outcomes from TAVR. ${ }^{69,70}$ These reports and other research projects have been greatly enhanced with linkages to the CMS database, which have allowed an assessment of longerterm outcomes and rehospitalization rates not captured in the STS/ACC TVT Registry.

The original purpose of clinical registries was to provide an assessment of the quality of care delivered and to enable quality improvement for sites utilizing data that they had submitted to the registry. National benchmarks are established by aggregating and analyzing the large volume of patients being treated at all sites whose data passes a quality and completeness check (Figure 4). This function of both the STS National Database and the STS/ACC TVT Registry is increasing in importance and the uses for derived quality metrics are expanding. Voluntary public reporting has started for cardiac surgery (http://publicreporting.sts.org/), PCI, and implantable cardioverter-defibrillator insertion (https://www. cardiosmart.org/Resources/Find-Your-Heart-a-Home) and will be launched for TAVR in the near future. Patients and others increasingly demand transparency of site performance reporting. In addition, assessment of care quality is increasingly linked to payment for services. Another use of registry-based assessment of a site's quality of care will start in 2019 with the publication of AUC for patients with severe AS that includes use of TAVR. ${ }^{23}$ Plans are underway to include the necessary data elements in the STS/ ACC TVT Registry to provide sites with standardized reports on the indication for TAVR in their patients. Site results are self-reported to the STS/ACC TVT Registry, and improvements in the completeness and accuracy of the data are part of an ongoing effort. The assessment of predicate site quality of care using valid measures and the multifaceted critical uses of performance metrics underscore the need for clinical registries and justify the time and expenses associated with data submission by sites.

In this update on TAVR, there has been an emphasis on the need for programs to monitor the quality of their care for both TAVR and SAVR. The 2 national registries provide regular reports to all participating sites that include risk-adjustment of key outcomes and national benchmarks that allow a site to compare themselves to others. This document on TAVR operator and institutional requirements also provides a blueprint for sites using these quarterly reports for the MDT to meet, discuss their results, and take actions to improve. 


\begin{tabular}{|c|c|c|c|}
\hline Current Timeframe Code & $\begin{array}{c}\text { Benchmark Inclusion } \\
\text { Status }\end{array}$ & Submission Type & $\begin{array}{c}\text { Included in Executive } \\
\text { Summary }\end{array}$ \\
\hline 2015 Q3 & G & All Patients & Yes \\
\hline $2015 Q 4$ & G & All Patients & Yes \\
\hline $2016 Q 1$ & G & All Patients & Yes \\
\hline $2016 Q 2$ & G & All Patients & Yes \\
\hline
\end{tabular}

$\begin{array}{cl}\begin{array}{c}\text { Benchmark Inclusion } \\ \text { Status }\end{array} & \begin{array}{l}\text { Indicates whether a submission will be included in the R4Q aggregated data } \\ \text { (benchmark) statistics. "Green, "Yellow" and "Red" stoplights denote this status. }\end{array}\end{array}$

A "Green" status indicates the submission (one quarter/timeframe) is included in the benchmark statistics. The data has successfully passed all data and assessment checks.

Y A "Yellow" status indicates the submission (one quarter/timeframe) is not included in the benchmark statistics. Data is displayed in the quarterly column, but is not included in the "My Hospital R4Q" summary. This data has not passed the overall completeness checks.

R A "Red" status indicates the submission (one quarter/timeframe) is not included in the benchmark statistics. Data is not displayed in the quarterly column.

A null or blank status indicates no submission has been received for that quarter/timeframe. Data is not displayed in the quarterly column.

FIGURE 4. STS/ACC TVT registry sample report on site-reported data passing a quality check.

One of the most crucial components of research is complete, accurate, and timely data submission from sites. Industry-sponsored research typically provides funding for data acquisition and follow-up at the site level. Intense monitoring of investigative sites, the use of core laboratories, and adjudication of endpoints are standard best practices in pivotal research studies. The STS/ACC TVT Registry uses site-reported data but without core laboratories and regular monitoring. The STS/ACC TVT Registry, via the Duke Clinical Research Institute, does adjudicate several key outcomes for TAVR. ${ }^{64}$ Both the STS/ACC TVT Registry and STS National Database use a thirdparty external audit to assess accuracy and completeness of data submission from sites. Site audits for the STS/ ACC TVT Registry underwent a pilot evaluation in 2016, and in 2017, regular audits have started using standards similar to those used by the STS National Database. The STS/ACC TVT Registry does have an extensive data quality initiative. ${ }^{71}$ Both the STS National Database and the STS/ACC TVT Registry provide feedback to sites on the quality and completeness of their data submission. Importantly, the STS/ACC TVT Registry requires sites to submit data on 1-year outcomes, whereas the STS National Database has focused on 30-day outcomes.
Additionally, the STS/ACC TVT Registry has incorporated several unique measurements of frailty and requires preprocedure, 30-day, and 1-year assessments of patientreported health status using the KCCQ questionnaire. These new measures and the 1-year follow-up requirement have challenged hospital sites, but in the last several years, there has been major progress in sites collecting these data in the majority of patients at 1 year. Both STS and NCDR have annual meetings for site data managers to provide them with best practices, networking opportunities, general education, and training to improve their data submission performance. For professional registries, the costs of data collection and submission fall upon the individual site. Reimbursement by CMS for TAVR is contingent on participation in this national registry, and the CMS should continue to understand real-life experience in a broad patient cohort and answer questions about long-term (1-year) survival and QoL after TAVR or SAVR.

\section{CRITERIA FOR ESTABLISHING A TAVR PROGRAM AND MAINTENANCE OF COMPETENCE}

This document includes requirements that are readily achievable by many sites and not considered exclusionary. 
TABLE 5. Examples of high-priority research topics for TAVR

\begin{tabular}{|c|c|}
\hline Topic & Background \\
\hline $\begin{array}{l}\text { Optimizing patient selection and } \\
\text { patient-centered outcomes: } \\
\text { preprocedure patient characteristics } \\
\text { and 1-year outcomes }\end{array}$ & $\begin{array}{l}\text { The benefit of TAVR in terms of survival with improved functional state and patient-reported health } \\
\text { status is achieved at } 1 \text { year in approximately two-thirds of patients who are inoperable or at high } \\
\text { risk for surgery. }{ }^{59} \text { On average, severe lung disease, undergoing dialysis, and/or very poor } \\
\text { baseline health status were associated with lower probability of benefit, but many with these } \\
\text { identifiers still benefitted. Can predictive models be developed that would guide patient selection } \\
\text { and shared decision-making more accurately? }\end{array}$ \\
\hline $\begin{array}{l}\text { Best practices in TAVR and SAVR } \\
\text { decision making }\end{array}$ & $\begin{array}{l}\text { The spectrum of patients with severe aortic stenosis is broad and includes those who may not } \\
\text { benefit from AVR due to extensive comorbidities, those receiving TAVR who are inoperable or at } \\
\text { high risk for SAVR, and those who could undergo TAVR and SAVR at low to intermediate risk. } \\
\text { The optimal process for the making of recommendations by multidisciplinary teams has not been } \\
\text { studied, and the incorporation of patient preferences involves a separate process that is not well- } \\
\text { described. }\end{array}$ \\
\hline $\begin{array}{l}\text { Real-world outcomes of TAVR in } \\
\text { patients with intermediate } \\
\text { surgical risk. }\end{array}$ & $\begin{array}{l}\text { Published trials of intermediate risk were conducted in highly selected sites using inclusion and } \\
\text { exclusion criteria. Real-world results from over } 500 \text { sites in the United States are likely to have a } \\
\text { more diverse patient population. Are outcomes comparable to those noted in clinical trials? }\end{array}$ \\
\hline $\begin{array}{l}\text { Incidence, timing, predictors, and } \\
\text { impact of permanent pacemakers } \\
\text { after TAVR using current-generation } \\
\text { TAVR technology and implantation } \\
\text { techniques. }\end{array}$ & $\begin{array}{l}\text { The need for permanent pacemakers following TAVR remains substantial. Increasingly, patients } \\
\text { are discharged within } 24-48 \text { hours after discharge, perhaps increasing the occurrence of CHB as } \\
\text { an outpatient event that could lead to sudden cardiac death. What is the optimal management to } \\
\text { minimize CHB and the best means of identifying those at risk? }\end{array}$ \\
\hline $\begin{array}{l}\text { TAVR site variations in patient selection, } \\
\text { procedure performance, site experience, } \\
\text { yearly case volumes, and outcomes }\end{array}$ & $\begin{array}{l}\text { With maturation of TAVR, there is a need to understand variations between hospitals in the type of } \\
\text { patients being treated, metrics of site performance, yearly case volume, and use of multiple } \\
\text { different TAVR technologies }\end{array}$ \\
\hline $\begin{array}{l}\text { Long-term durability of bioprosthetic TAVR } \\
\text { and SAVR valves for both native aortic } \\
\text { valve disease and treatment of degenerated } \\
\text { SAVR valves }\end{array}$ & $\begin{array}{l}\text { As more patients are treated, the burden of comorbid conditions is lowered. It is expected that their } \\
\text { increased survival of 5-10 years post-TAVR will provide the opportunity to assess the incidence, } \\
\text { frequency, and associated factors leading to structural valve deterioration }\end{array}$ \\
\hline $\begin{array}{l}\text { Frequency of leaflet thrombosis of tissue valves, } \\
\text { time of onset, association with clinical events, } \\
\text { modification with anticoagulation, and optimal } \\
\text { duration of anticoagulation }\end{array}$ & $\begin{array}{l}\text { Recent data show leaflet thrombosis occurs in } 13 \% \text { of TAVR bioprosthetic valves and } 4 \% \text { of SAVR } \\
\text { bioprosthetic valves. }{ }^{72} \text { The median time from SAVR to CT scanning was } 163 \text { days (IQR: 79-417 } \\
\text { days), and from TAVR to CT scanning, } 58 \text { days (IQR: } 32-236 \text { days). Warfarin and DOACs were } \\
\text { effective in preventing and resolving leaflet thrombus. Leaflet thrombus was associated with TIA } \\
\text { and increased TAVR valve pressure gradients }\end{array}$ \\
\hline
\end{tabular}

$T A V R$, Transcatheter aortic valve replacement; $S A V R$, surgical aortic valve replacement; $C H B$, complete heart block; $C T$, computed tomography; IQR, interquartile range; $D O A C$, direct oral anticoagulant; TIA, transient ischemic attack.

In addition, the requirements are considered clinically reasonable on the basis of expert opinion and are supported by data/evidence whenever possible. The 3 overall goals of these requirements are

1. To promote high standards regarding the quality of care for all patients with AS, whether they receive TAVR, SAVR, medical therapy, or palliative care

2. To establish a blueprint for every TAVR site to have a process for critical self-examination of their program's performance of AVR, both TAVR and SAVR, as well as for continuous improvement using the objective data provided by national benchmarks from the STS/ ACC TVT Registry

3. To ensure patient evaluation and care decisions are performed with a patient-family focus that incorporates SDM with respect to the relevant goals of the patient and their medical care preferences.

\subsection{Requirements and Recommendations for New TAVR Programs}

Because TAVR is now a widely available and standard form of therapy, an institution should not initiate a TAVR program with a completely inexperienced MDT. New programs should have in place processes for optimizing treatment selection and SDM, as outlined in the previous text. The specific requirements for a new TAVR program (Table 4), encompassing issues such as TAVR-specific experience and training, are as follows:

TAVR Proceduralist: A specific requirement for the initiation of a new TAVR site is a full-time board-eligible or certified (in interventional cardiology or cardiothoracic surgery) primary TAVR operator. The primary TAVR operator should be a member of the MDT at the designated new institution where he or she spends at least $50 \%$ of active practice time. The TAVR proceduralist should 
possess prior experience at an active TAVR site and have participated in at least 100 transfemoral TAVR cases with at least 50 cases as primary operator. Either a training program director or TAVR medical director from an institution with an existing TAVR program should document prior case volume. If the primary proceduralist is a surgeon, then the other physician needs to be an interventional cardiologist.

TAVR Surgeon: The cardiac surgeon must have performed at least 100 SAVRs in his or her lifetime or 50 SAVRs over 2 years with at least 20 SAVRs in the past year prior to initiation of the TAVR program. Also, the same surgeon should spend at least $50 \%$ of his/her active practice in the TAVR hospital.

Alternative-Access TAVR: New TAVR programs should obtain adequate volume and outcomes in transfemoral TAVR before considering expansion to patients requiring alternative access. Prior to expanding into alternative access, a new TAVR program should first complete at least 80 TAVRs using transfemoral access with an STS/ACC TVT Registry 30-day all-cause mortality above the bottom $25 \%$ of all TAVR programs for 2 consecutive quarters/year. The writing committee's consensus regarding the required 80 TAVR procedures was based on information from referenced articles and expert opinion. ${ }^{7,9,10,73-80}$ Alliances should be established between low-volume, high-quality programs serving geographic isolated areas or programs caring for underserved populations and high-volume, high-quality programs to care for patients needing alternative access and the higher-risk complex patient population needing TAVR.

SAVR Program: A TAVR site should include an active open SAVR program to ensure the full spectrum of care options is offered and to provide optimal patient-specific treatment. This will also ensure the new site will have experience with TAVR complications and occasional crossovers to SAVR. The new hospital site should have a minimum of 2 hospital-based, board-eligible or -certified (American Board of Thoracic Surgery) cardiac surgeons whose active practice time is at least $50 \%$ at the TAVR/ SAVR-specific hospital. The site hospital should have performed at least 40 SAVRs in the prior year or 80 procedures over the prior 2 years. The new site hospital should also demonstrate active quality assessment/quality improvement with active participation in the STS National Database. Documentation of SAVR performance of the various SAVR-type procedures described in the previous text as well as SAVR plus CABG will be required with an STS rating of at least 2 stars for $\geq 2$ consecutive reporting periods in the past year.

Managing TAVR-Related Issues: Minimum volume requirements for PCI and SAVR for new programs reflect the process, infrastructure, and commitment needed for establishing a comprehensive aortic valve program.
Programs need to demonstrate experience in PCI, vascular interventions, and SAVR. All programs should meet minimum quality metrics for clinical outcomes. It is expected that new and existing programs are gathering data on PCI via a National Quality Forum-endorsed registry and on SAVR via the STS National Database. Therefore, the 2018 criteria for a new program include a minimum volume of 300 PCIs per year with active participation in the NCDR/Cath PCI Registry or a validated state/multiinstitutional database that gathers adequate data elements and provides analysis such that individual sites can assess performance with benchmarks for the key domains of patient selection, procedure performance, and clinical outcomes. In addition, a performance level should be maintained using the quality metric for in-hospital PCI mortality (National Quality Forum-endorsed) above the bottom $25 \%$ of programs. The institution should also have experience and competence in vascular arterial interventions (which include thoracic endovascular aortic repair/endovascular aneurysm repair; carotid, renal artery, femoral artery, and coarctation stenting; and acute limb ischemia-related interventions) to demonstrate its ability to handle TAVR access issues and complications. In addition, the institution should possess an active cardiac pacemaker program with experienced, competent physicians for both temporary and permanent pacemaker placement and management. These on-site services should be available $24 \mathrm{~h}$ /day and 7 days/week to handle conduction disturbances after TAVR.

Individual Site Requirement: Each site within a hospital system should meet the minimum procedural volume, TVT registry, and TAVR personnel requirements to be eligible to become an active TAVR program. Also, each site within a system should have proceduralists and surgeons who spend at least $50 \%$ of their active practice time at that particular site and meet the minimum requirements of procedures for eligibility at that site to become a program. There will be no blanket eligibility for additional sites within a system based on the fact that 1 site within that system met eligibility requirements.

\subsection{Requirements and Recommendations for Existing TAVR Programs}

There will be a 2-year period to allow new programs to "bridge," grow, and develop from a new to an established program prior to the need to fulfill the requirements for an established program. By the 3rd year, new programs should have acquired sufficient experience for volume and outcomes analysis, although earlier clusters of poor outcomes require attention even if not yet statistically verified. Realtime performance-monitoring techniques, such as cumulative sum or Variable Life Adjustment Display curves, have been used effectively to monitor safety as new techniques are introduced. ${ }^{81-87}$ 
Table 3 outlines the requirements for continued certification for existing TAVR programs, including procedure volume, essential personnel, infrastructure, quality assessment/quality improvement processes, and acceptable levels of performance on outcomes. Existing TAVR programs, like new TAVR programs, should have in place the processes and SDM outlined in the previous text. This includes documentation of a multidisciplinary approach and patient access to all forms of AVR.

Minimal TAVR volume requirements for TAVR proceduralists in new programs are based on expert opinion and evidence regarding the association of volume with procedural safety, efficiency, and patient outcomes. $7,9,10,12,88-90$

TAVR volume and outcomes are gathered for commercial TAVR implants in the STS/ACC TVT Registry. A site may have additional TAVR volume from clinical trials. The STS/ ACC TVT Registry will be used as the tool to provide clinical outcomes for individual sites to benchmark their performance in relation to the national performance level. For outcomes that are risk adjusted, a program's results are judged against what would be expected for their specific case mix on the basis of data from the entire population of TAVR programs. These risk-adjusted outcomes metrics are useful not only for external review, but also for performance evaluation to focus quality improvement initiatives.

The quantity and quality of care standards are more extensive for existing TAVR programs than for new ones. They include performance metrics based on national benchmarks, which are derived from analyses of data from all existing TAVR programs that have submitted data meeting the completeness and quality standards set by the STS/ACC TVT Registry. An existing TAVR program should perform at least 50 TAVRs per year or 100 TAVRs over 2 years and maintain an STS/ACC TVT Registry score above the bottom $10 \%$ for metrics outlined in Table 1 . Quality metrics must be monitored, including 1-year survival and functional improvement as assessed by KCCQ.

Additionally, TAVR programs should maintain a minimum hospital volume of 30 SAVRs per year or 60 SAVRs over 2 years and an STS rating of $\geq 2$ stars for at least 2 consecutive performance reporting periods per year for both AVR and AVR plus CABG (or analogous quality standards if only participating in other state or national registry). The institution should also maintain and document consistent resources, experience, and quality outcomes for PCI, vascular interventions, and pacemaker capabilities as outlined in Table 3.

On a quarterly basis, the MDT from each site should have a documented meeting to analyze and compare their own quarterly STS/ACC TVT Registry data with the benchmark standards within the registry. If site performance is suboptimal relative to either volume or quality performance metrics, the MDT should outline a continuous quality improvement action plan. In addition, a quarterly mortality and morbidity MDT conference should be documented, with selected cases presented and discussed as well as quality improvement actions initiated and measurement tools implemented to assess the results of those actions. The MDT should also have a weekly meeting that follows a standardized process to present and discuss appropriateness of TAVR/SAVR patient selection. It is expected that all members of the MDT will participate in appropriate continuing medical education (CME).

\subsection{Requirements for SAVR}

Truly patient-centered decision making requires a nuanced discussion of all options open to the patient. Ideally, both TAVR and open SAVR options should be discussed with every patient considering AVR.

SAVR is performed today in large numbers and at low risk. A review of isolated AVR in U.S. practice from 2001 to 2010 demonstrated an overall operative mortality rate of $3.0 \%$, with $80.0 \%$ of patients having an STSPROM $<4 \%$ using the STS risk model. ${ }^{91}$ The observed operative mortality rate among this lowest-risk stratum was $1.7 \%$. As is the case for TAVR, observed mortality and morbidity rates have continued to decline over time. Whereas TAVR observed mortality has declined from $5.7 \%$ to $2.9 \%$ in the face of changing STS-PROM $(7 \%$ to $6 \%$ per the STS model and $4 \%$ to $3 \%$ per the TVT model), ${ }^{70}$ observed surgical mortality has remained stable in the lowest risk groups but declined in the intermediateand high-risk groups (from $6.4 \%$ to $5.4 \%$ [intermediate risk, $<4 \%$ to $8 \%$ STS-PROM]; and $14.4 \%$ to $11.9 \%$ [high risk $>8 \%$ STS-PROM]). The stroke rate has remained stable at $1.5 \%$ overall just as it has for TAVR $(2.1 \%)$. Interest in minimally invasive approaches to further reduce morbidity are encouraging, with data suggesting reductions in blood transfusion and pain scores as well as improved respiratory function associated with alternative incisions. ${ }^{92}$

Many studies have demonstrated a volume-outcomes relationship for SAVR, ${ }^{93-98}$ as is the case for many other

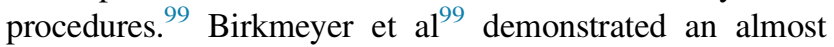
$30 \%$ lower mortality rate $(9.1 \%$ vs $6.5 \%)$ for SAVR performed by high-volume $(>42 / \mathrm{y})$ versus low-volume $(<22 /$ y) surgeons using the Medicare claims administrative database. A hospital volume effect was observed as well for SAVR but was $100 \%$ attributable to surgeon volume in their study. These same investigators demonstrated that the volume effect holds true for both high- and low-risk patients. ${ }^{100}$ In contrast, Patel et al. ${ }^{94}$ demonstrated the opposite, a hospital volume effect but no surgeon volume effect, in Michigan in a more recent study performed using a statewide clinical database. This demonstrates the challenges of utilizing alternate database sources but confirms the existence of an outcomes/volume relationship. Unsurprisingly, an outcomes/ 
volume relationship holds for the more complex aortic root replacement procedures. ${ }^{101,102}$

Importantly, SAVR also makes possible a variety of complex reparative procedures, such as associated atrial fibrillation ablation procedures and implantation of a variety of prostheses ranging from human allografts ("homografts") to current-generation tissue valves and mechanical prostheses. Furthermore, the pulmonary autograft operation may restore the patient to the expected survival curve for an age-matched population. ${ }^{103}$ Arguably, the decision between prosthetic options, including both tissue and mechanical valves, should be presented first because TAVR restricts one to a tissue option.

Just as there has been remarkable technological progress in transcatheter prostheses, improvements in both tissue and mechanical prostheses are lessening the burden of "prosthetic valve disease." Currently employed surgical valve designs demonstrate freedom from explant due to structural valve deterioration as low as $5.4 \%$ in 1 large, singleinstitution study ${ }^{104}$ and actuarial freedom from structural valve deterioration at 15 years of $78.6 \%$ and expected valve durability of 19.7 years in another study. ${ }^{105}$ The durability of currently available fourth-generation tissue valves is yet to be seen, but improvements in design are increasing the use of tissue prostheses. Whereas the traditional standard used to assess durability of SAVR valves has been reoperation, the standards currently being applied to TAVR valves are more stringent and based on changes in pressure gradients and degree of central aortic regurgitation that may or may not be associated with symptoms. Ongoing studies have begun applying the same metrics to SAVR and TAVR valves in randomized trials in low-risk patients.

The evolution of $\mathrm{ViV}$ deployment of TAVR prostheses offers an alternative approach to dealing with tissue valve degeneration, although the operative risk reported with open reoperation is low. ${ }^{106}$ Recently, the use of highpressure balloons to fracture failed surgical implants to facilitate larger TAVR implants has been described. ${ }^{107,108}$ The $\mathrm{ViV}$ option has important implications for planning the initial implant, including favoring larger prostheses to minimize the anticipated gradient after ViV deployment. A controversial question concerns the advisability of adding aortic root enlargement to accomplish this aim, although evidence suggests there is no increased operative risk in experienced hands. ${ }^{109}$ The ViV consideration may also favor stented over stentless xenograft procedures. ${ }^{110}$

Mechanical valve prostheses continue to play an important role despite the secular momentum in favor of placing tissue valves even in younger patients. Recent populationbased data support arguments that, despite this trend, there may be a survival advantage associated with mechanical valves among patients in the 50- to 69 -year age range. ${ }^{111}$ This is particularly important as TAVR indications are expanded to patients with ever lower and lower risk.
Progress in mechanical valve design has focused on improved biocompatibility permitting lower target international normalized ratio. A recent prospective randomized study demonstrated the safety of a lower target international normalized ratio of 1.5 to 2.0 for a new-generation mechanical valve, with resultant reduction in major bleeding events by over half at no increased risk of stroke. ${ }^{112}$ A reduction in bleeding events without increase in thromboembolism has also been demonstrated when telemedicine-guided anticoagulation with home testing is employed. ${ }^{113}$ Use of these new-generation mechanical valves with home international normalized ratio testing has shown bleeding and thromboembolism rates comparable to tissue prostheses and suggests a mortality benefit at 7.5 years for mechanical valves over tissue in patients younger than age 65 years. ${ }^{114}$

The role of aortic valve repair procedures continues to be explored, offering hope for a solution free of "prosthetic valve disease," with its risks of thrombosis, bleeding, infection, and structural deterioration. ${ }^{115}$ Valve-sparing and preserving interventions on the aortic root are also gaining wider application as an alternative to composite root replacement. $^{116}$

\subsubsection{SAVR-Only Programs}

In an effort to attain equivalence for the care of patients with aortic valve disease at all institutions, emphasis at SAVR-only sites must be placed on the larger context and specifically on the broader goal of optimizing patient care. Therefore, programs that offer SAVR only should have the resources and processes in place to ensure adherence to the following recommendations:

1. Presence of an MDT. The rationale for this is that no one individual, group, or specialty possesses all the necessary skills for optimal patient outcomes ${ }^{13,17}$ and that the success of these programs depends on a group of professionals working together, each with his or her own skillset, to provide the best possible patientcentered care. The MDT is an essential requirement.

2. MDT evaluation of patients. This should include a thorough clinical and laboratory evaluation, as well as appropriate cardiac imaging (electrocardiogram, echocardiogram, coronary angiography, and computed tomography as needed). Details are in Section 3.2. The MDT incorporates relevant professional management guidelines and AUC for all forms of care, including TAVR, SAVR, medical therapy, and palliative care.

3. Incorporation of best practices for educating patients and their families. The rationale for broad and extensive education is to facilitate true SDM by the patient and designated family/caregivers and clinicians.

4. Implementation of patient-family SDM that incorporates patient preferences. The patient and family are first priority in SDM with respect to the relevant goals 
of the patient and his or her medical care preferences, even if this means losing the patient to another institution.

5. Documentation by the MDT that each patient has been made aware of all types of techniques for AVR as well as the risks and benefits of each, whether the patient is a candidate for treatment with TAVR, SAVR, or both forms of therapy. In addition, the patient should be informed about which therapies are available at the hospital. The volume and outcomes for AVR for the site should be discussed with the patient. This sets the stage for SDM with the key element of incorporating patient preferences.

6. Education of patients regarding the MDT's recommendations regarding different treatment options, which are based on objective and validated resources and decision aids.

7. Submission of data on all commercial SAVR cases to the STS National Database. This is an NCD requirement for all SAVR technologies.

8. Process of self-examination. Every SAVR-only site must have a process for critical self-examination of its program's AVR performance, as well as a process for continuous improvement using the objective data provided by national benchmarks from the STS National Database.

To ensure that patients are meaningfully participating in SDM, each SAVR program should ensure that patients: (1) are well-informed regarding their options; (2) understand risks and benefits presented using validated objective data on treatment options that are as patient-specific as possible; (3) articulate their treatment-related goals; (4) identify their preferences and values in relation to their care; and (5) synthesize this knowledge of options, risks and benefits, goals, preferences, and values to make a final treatment choice.

\section{COMPLIANCE WITH DOCUMENT RECOMMENDATIONS}

Professional societies have worked diligently to develop fair and objective requirements for institutions and individual operators who are part of new and existing TAVR programs, with the main goal of optimizing the quality of care for patients with aortic valve disease.

Compliance with professional society recommendations, while voluntary, is expected. This document provides institutions with a blueprint for monitoring program outcomes for TAVR and SAVR and for developing and maintaining a quality improvement program.

The CMS NCD documents have been in effect since 2012. For TAVR, the NCD is currently based on compliance with the institutional and operator requirements listed in the Multisociety (AATS, ACCF, SCAI, and STS) Expert Consensus Statement: Operator and Institutional
Requirements for Transcatheter Valve Repair and Replacement, Part 1: Transcatheter Aortic Valve Replacement. ${ }^{1}$ Compliance with the NCD for TAVR allows coverage and payment from Medicare. CMS has the right to deny coverage and the ability to sunset the NCD document when the key questions have been satisfactorily answered.

This writing committee recommends that the STS/ACC TVT Registry and the STS National Database and their parent professional societies undertake following actions:

- Produce an annual report using adjusted outcomes based on stable and well-validated statistical models that is available, published in professional journals, provided to $\mathrm{CMS}$, and contains the following summary statistics:

- Number of all active TAVR sites and frequency distribution of yearly site volume. The report should identify the number and percentage of active TAVR sites whose yearly volume falls below the minimum requirements outlined in this document.

- Number of all active SAVR sites and frequency distribution of yearly site volume. The report should identify the number and percentage of active SAVR sites whose yearly volume falls below the minimum requirement for a complementary TAVR program. For the purposes of this document, the hospital volume requirement for SAVR is defined as including all AVR (mechanical, bioprosthesis, homograft, autograft [Ross], composite valve graft, and root replacement) and aortic valve repair procedures, including concomitant valve resuspension for acute aortic dissection and valve-sparing aortic root replacement, performed alone or in conjunction with other cardiac procedures. Simple adjuvant aortic valve procedures (eg, suturing closed regurgitant aortic valves in an LV assist device patient, excising a papillary fibroelastoma or thrombus) are not counted.

- Number of active TAVR sites that both meet and fail to meet the data quality and completeness requirements of the STS/ACC TVT Registry.

- Number of active SAVR sites that both meet and fail to meet the data quality and completeness requirements of the STS National Database.

- Number of TAVR sites that meet and fail to meet the outcomes standards outlined in Table 1.

- Number of SAVR sites that achieve each category of star rating.

- TAVR and SAVR sites that fail to meet volume, quality of care, and compliance for reporting performance metrics as outlined in this document should receive a letter from the relevant national registry informing them of this finding.

- Professional societies should consider means of helping sites and physicians who are failing to meet the quality 
of care and compliance for reporting performance metrics for TAVR and SAVR.

Professional societies should work with all stakeholders to ensure recommendations are met in a manner that ensures quality care.

\section{CONCLUSIONS}

TAVR has matured as a therapeutic option for patients requiring AVR.

In the prior 2012 document, ${ }^{1}$ the operator requirements were based on skills that would be necessary to perform TAVR. At this time, it is felt that such skills are best learned by doing TAVR. Therefore, the prerequisite skills have been replaced by TAVR experience. The 2018 document provides additional quality metrics that complement requirements that were surrogates for TAVR skills as indicators for quality of care as presented in the 2012 document. ${ }^{1}$ TAVR case volume requirements provide a structural measure to ensure foundational data minimums.

This remains an evolving field with continual changes in indications, equipment, technique, and clinical outcomes. As the indications expand to younger patients, assessing the structural durability of the valve is critical. This document reflects the current state of the art and is designed to evolve with the field.

\section{References}

1. Tommaso CL, Bolman RM 3rd, Feldman T, et al. Multisociety (AATS, ACCF, SCAI, and STS) expert consensus statement: operator and institutional requirements for transcatheter valve repair and replacement, part 1: transcatheter aortic valve replacement. J Am Coll Cardiol. 2012;59:2028-42.

2. Leon MB, Smith CR, Mack MJ, et al. Transcatheter or surgical aortic-valve replacement in intermediate-risk patients. N Engl J Med. 2016;374:1609-20.

3. Thourani VH, Kodali S, Makkar RR, et al. Transcatheter aortic valve replacement versus surgical valve replacement in intermediate-risk patients: a propensity score analysis. Lancet. 2016;387:2218-25.

4. Reardon MJ, Van Mieghem NM, Popma JJ, et al. Surgical or transcatheter aortic-valve replacement in intermediate-risk patients. $N$ Engl J Med. 2017; 376:1321-31.

5. Donabedian A. The quality of care. How can it be assessed? JAMA. 1988;260: 1743-8.

6. Institute of Medicine. Performance Measurement: Accelerating Improvement (Pathways to Quality Health Care Series)/Edition 1. Washington, DC: National Academies Press; 2006.

7. Alli O, Rihal CS, Suri RM, et al. Learning curves for transfemoral transcatheter aortic valve replacement in the PARTNER-I trial: technical performance. Catheter Cardiovasc Interv. 2016;87:154-62.

8. Tommaso CL. Learning curves for TAVR: not quite see one, do one teach one. Catheter Cardiovasc Interv. 2016;87:163-4.

9. Minha S, Waksman R, Satler LP, et al. Learning curves for transfemoral transcatheter aortic valve replacement in the PARTNER-I trial: success and safety. Catheter Cardiovasc Interv. 2016;87:165-75.

10. Suri RM, Minha S, Alli O, et al. Learning curves for transapical transcatheter aortic valve replacement in the PARTNER-I trial: technical performance, success, and safety. J Thorac Cardiovasc Surg. 2016;152:773-780.e14.

11. Alkhouli MA, Raybuck BD, Badhwar V. Navigating the s-curve of transapical therapy. J Thorac Cardiovasc Surg. 2016;152:781-2.

12. Carroll J, Vemulapalli S, Dai D, et al. The association between procedural experience for transcatheter aortic valve replacement and outcomes: insights from the STS/ACC TVT Registry. J Am Coll Cardiol. 2017;70:29-41.
13. Holmes DR Jr, Mack MJ, Kaul S, et al. 2012 ACCF/AATS/SCAI/STS expert consensus document on transcatheter aortic valve replacement. J Am Coll Cardiol. 2012;59:1200-54.

14. Vassiliades TA Jr, Block PC, Cohn LH, et al. The clinical development of percutaneous heart valve technology: a position statement of the Society of Thoracic Surgeons (STS), the American Association for Thoracic Surgery (AATS), and the Society for Cardiovascular Angiography and Interventions (SCAI) Endorsed by the American College of Cardiology Foundation (ACCF) and the American Heart Association (AHA). J Am Coll Cardiol. 2005;45:1554-60.

15. Otto CM, Kumbhani DJ, Alexander KP, et al. 2017 ACC expert consensus decision pathway for transcatheter aortic valve replacement in the management of adults with aortic stenosis: a report of the American College of Cardiology Task Force on Clinical Expert Consensus Documents. J Am Coll Cardiol. 2017;69: 1313-46.

16. Hyman MC, Vemulapalli S, Szeto WY, et al. Conscious sedation versus genera anesthesia for transcatheter aortic valve replacement: insights from the National Cardiovascular Data Registry Society of Thoracic Surgeons/American College of Cardiology Transcatheter Valve Therapy Registry. Circulation. 2017;136: 2132-40.

17. Herrmann HC, Baxter S, Ruiz CE, Feldman TE, Hijazi ZM, for the SCAI Council on Structural Heart Disease. Results of the Society of Cardiac Angiography and Interventions survey of physicians and training directors on procedures for structural and valvular heart disease. Catheter Cardiovasc Interv. 2010;76: E106-10.

18. Cameron AA, Laskey WK, Sheldon WC, for the Society for Cardiovascular Angiography and Interventions (SCAI) Ad Hoc Task Force On Ethics in Invasive and Interventional Cardiology. Ethical issues for invasive cardiologists: Society for Cardiovascular Angiography and Interventions. Catheter Cardiovasc Interv. 2004;61:157-62.

19. Kouchoukos NT, Bavaria JE, Coselli JS, et al. Guidelines for credentialing of practitioners to perform endovascular stent-grafting of the thoracic aorta. J Thorac Cardiovasc Surg. 2006;131:530-2.

20. Beller GA, Winters WL Jr, Carver JR, King SB 3rd, McCallister BD, Popp RL. 28th Bethesda Conference. Task force 3: guidelines for credentialling practicing physicians. J Am Coll Cardiol. 1997;29:1148-62.

21. Leon MB, Piazza N, Nikolsky E, et al. Standardized endpoint definitions for transcatheter aortic valve implantation clinical trials: a consensus report from the Valve Academic Research Consortium. J Am Coll Cardiol. 2011;57: 253-69.

22. Bashore TM, Balter S, Barac A, et al. 2012 American College of Cardiology Foundation/Society for Cardiovascular Angiography and Interventions expert consensus document on cardiac catheterization laboratory standards update: a report of the American College of Cardiology Foundation Task Force on Expert Consensus documents developed in collaboration with the Society of Thoracic Surgeons and Society for Vascular Medicine. J Am Coll Cardiol. 2012;59: 2221-305.

23. Bonow RO, Brown AS, Gillam LD, et al. ACC/AATS/AHA/ASE/EACTS/ HVS/SCA/SCAI/SCCT/SCMR/STS 2017 appropriate use criteria for the treatment of patients with severe aortic stenosis: a report of the American College of Cardiology Appropriate Use Criteria Task Force, American Association for Thoracic Surgery, American Heart Association, American Society of Echocardiography, European Association for Cardio-Thoracic Surgery, Heart Valve Society, Society of Cardiovascular Anesthesiologists, Society for Cardiovascular Angiography and Interventions, Society of Cardiovascular Computed Tomography, Society for Cardiovascular Magnetic Resonance, and Society of Thoracic Surgeons. J Am Coll Cardiol. 2017;70:2566-98.

24. Sepucha KR, Wasfy JH. Implementing shared decision making in the rapidly evolving field of valvular heart disease. Circ Cardiovasc Qual Outcomes. 2017; 10:e003549.

25. Advice. Navigating Aortic Valve Treatment Choices. Available at: http://www. valveadvice.org.php56-7.ord1-1.websitetestlink.com/. Accessed April 2, 2017.

26. Centers for Medicare \& Medicaid Services. Beneficiary engagement and incentives (BEI) models: shared decision making (SDM) model. Available at: https://innovation.cms.gov/Files/slides/bei-sdm-overviewloi_slides.pdf. Accessed April 24, 2017.

27. Centers for Medicare \& Medicaid Services. National Coverage Determination (NCD) for transcatheter aortic valve replacement (TAVR). Available at: https:// Www.cms.gov/medicare-coverage-database/details/ncd-details.aspx?NCDid= $355 \&$ ncdver $=1 \&$ NCAid $=257 \&$ ver $=4 \&$ NcaName $=$ Transcatheter + Aortic + Valve + Replacement $+\% 28$ TAVR $\% 29 \& b c=$ ACAAAAAACAAAAA $\% 3$ D $\%$ 3D\&.\%20. Accessed April 1, 2017. 
28. American College of Cardiology Foundation, Society of Thoracic Surgeons. STS/ACC TVT Registry. Available at: https://www.ncdr.com/webncdr/tvt/ publicpage/home. Accessed April 2, 2017.

29. Arnold SV, Spertus JA, Lei Y, et al. How to define a poor outcome after transcatheter aortic valve replacement: conceptual framework and empirical observations from the placement of aortic transcatheter valve (PARTNER) trial. Circ Cardiovasc Qual Outcomes. 2013;6:591-7.

30. Green P, Arnold SV, Cohen DJ, et al. Relation of frailty to outcomes after transcatheter aortic valve replacement (from the PARTNER trial). Am J Cardiol. 2015; 116:264-9.

31. Lindman BR, Alexander KP, O'Gara PT, Afilalo J. Futility, benefit, and transcatheter aortic valve replacement. J Am Coll Cardiol Intv. 2014;7:707-16.

32. Arnold SV, Spertus JA, Vemulapalli S, et al. Association of patient-reported health status with long-term mortality after transcatheter aortic valve replacement: report from the STS/ACC TVT Registry. Circ Cardiovasc Interv. 2015; 8:e002875.

33. Puls M, Sobisiak B, Bleckmann A, et al. Impact of frailty on short- and longterm morbidity and mortality after transcatheter aortic valve implantation: risk assessment by Katz Index of activities of daily living. EuroIntervention. 2014;10:609-19.

34. Puri R, Iung B, Cohen DJ, Rodes-Cabau J. TAVI or no TAVI: identifying patients unlikely to benefit from transcatheter aortic valve implantation. Eur Heart J. 2016:37:2217-25.

35. Schoenenberger AW, Stortecky S, Neumann S, et al. Predictors of functional decline in elderly patients undergoing transcatheter aortic valve implantation (TAVI). Eur Heart J. 2013:34:684-92.

36. Kapadia SR, Leon MB, Makkar RR, et al. 5-year outcomes of transcatheter aortic valve replacement compared with standard treatment for patients with inoperable aortic stenosis (PARTNER 1): a randomised controlled trial. Lancet. 2015;385:2485-91.

37. Mack MJ, Leon MB, Smith CR, et al. 5-year outcomes of transcatheter aortic valve replacement or surgical aortic valve replacement for high surgical risk patients with aortic stenosis (PARTNER 1): a randomised controlled trial. Lancet. 2015:385:2477-84.

38. Price S, Haxby E. Managing futility in critically ill patients with cardiac disease. Nat Rev Cardiol. 2013;10:723-31.

39. Carabello BA. TAVR: A good fix, but it cannot fix everything. JACC Cardiovasc Interv. 2016;9:2555-6.

40. Arnold SV, Afilalo J, Spertus JA, et al. Prediction of poor outcome after transcatheter aortic valve replacement. J Am Coll Cardiol. 2016;68:1868-77.

41. Hlatky MA, Simons CT. Cost-effectiveness of transcatheter aortic valve replacement. Circulation. 2012;125:1076-7.

42. Frigerio M, Bruschi G, Klugmann S. Letter by Frigerio et al regarding article, "Long-term outcomes of inoperable patients with aortic stenosis randomly assigned to transcatheter aortic valve replacement or standard therapy." Circulation. 2015;132:e117.

43. Allen LA, Rumsfeld JS. Can we predict who will be alive and well after transcatheter aortic valve replacement? Is that useful to individual patients? Circulation. 2014;129:2636-7.

44. O’Sullivan CJ, Wenaweser P. Can we predict quality of life and survival after transcatheter aortic valve replacement? Circ Cardiovasc Interv. 2015;8: $\mathrm{e} 003347$.

45. Herrmann H, Han Y. Identifying patients who do not benefit from transcatheter aortic valve replacement. Circ Cardiovasc Interv. 2014;7:136-8.

46. Allende R, Webb JG, Munoz-Garcia AJ, et al. Advanced chronic kidney disease in patients undergoing transcatheter aortic valve implantation: insights on clinical outcomes and prognostic markers from a large cohort of patients. Eur Heart J. 2014:35:2685-96.

47. Ferro CJ, Chue CD, de Belder MA, et al. Impact of renal function on survival after transcatheter aortic valve implantation (TAVI): an analysis of the UK TAVI registry. Heart. 2015;101:546-52.

48. Gargiulo G, Capodanno D, Sannino A, et al. Moderate and severe preoperative chronic kidney disease worsen clinical outcomes after transcatheter aortic valve implantation: meta-analysis of 4992 patients. Circ Cardiovasc Interv. 2015;8: e002220.

49. Kobrin DM, McCarthy FH, Herrmann HC, et al. Transcatheter and surgical aortic valve replacement in dialysis patients: a propensity-matched comparison. Ann Thorac Surg. 2015;100:1230-6; discussion 6-7.

50. Holmes DR Jr, Brennan JM, Rumsfeld JS, et al. Clinical outcomes at 1 year following transcatheter aortic valve replacement. JAMA. 2015;313:1019-28.
51. Mok M, Nombela-Franco L, Dumont E, et al. Chronic obstructive pulmonary disease in patients undergoing transcatheter aortic valve implantation: insights on clinical outcomes, prognostic markers, and functional status changes. J Am Coll Cardiol Intv. 2013;6:1072-84.

52. Suri RM, Gulack BC, Brennan JM, et al. Outcomes of patients with severe chronic lung disease who are undergoing transcatheter aortic valve replacement. Ann Thorac Surg. 2015;100:2136-45; discussion 45-6.

53. Herrmann HC, Pibarot P, Hueter I, et al. Predictors of mortality and outcomes of therapy in low-flow severe aortic stenosis: a Placement of Aortic Transcatheter Valves (PARTNER) trial analysis. Circulation. 2013;127: 2316-26.

54. Nombela-Franco L, Ribeiro HB, Urena M, et al. Significant mitral regurgitation left untreated at the time of aortic valve replacement: a comprehensive review of a frequent entity in the transcatheter aortic valve replacement era. J Am Coll Cardiol. 2014;63:2643-58.

55. Nishimura RA, Otto CM, Bonow RO, et al. 2017 AHA/ACC focused update of the 2014 AHA/ACC Guideline for the Management of Patients With Valvular Heart Disease: a report of the American College of Cardiology/American Heart Association Task Force on Clinical Practice Guidelines. J Am Coll Cardiol. 2017;70:252-89.

56. CardioSmart. A decision aid for treatment options for severe aortic stenosis for patients deciding between TAVR and surgery: for patients with immediate or high surgical risk. Available at: https://www.cardiosmart.org/ /media/ Documents/Decision\%20Aids/Aortic-Stenosis_TAVR-surgery.ashx. Accessed November 2, 2017.

57. CardioSmart. A decision aid for treatment options for severe aortic stenosis (TAVR vs symptom management): for patients with prohibitive surgical risk/ inoperable. Available at: https://www.cardiosmart.org/ /media/Documents/ Decision\%20Aids/Aortic-Stenosis_TAVR-manage-symptoms.ashx. Accessed November 2, 2017.

58. Shahian DM, He X, Jacobs JP, et al. The Society of Thoracic Surgeons Isolated Aortic Valve Replacement (AVR) Composite Score: a report of the STS Quality Measurement Task Force. Ann Thorac Surg. 2012;94:2166-71.

59. Arnold SV, Spertus JA, Vemulapalli S, et al. Quality-of-life outcomes after transcatheter aortic valve replacement in an unselected population: a report from the STS/ACC Transcatheter Valve Therapy Registry. JAMA Cardiol. 2017;2:409-16.

60. Arnold SV, Spertus JA, Lei Y, et al. Use of the Kansas City Cardiomyopathy Questionnaire for monitoring health status in patients with aortic stenosis Circ Heart Fail. 2013;6:61-7.

61. Edwards FH, Cohen DJ, O'Brien SM, et al. Development and validation of a risk prediction model for in-hospital mortality after transcatheter aortic valve replacement. JAMA Cardiol. 2016;1:46-52.

62. Spiegelhalter D. Funnel plots for institutional comparison. Qual Saf Health Care. 2002;11:390-1.

63. Spiegelhalter DJ. Funnel plots for comparing institutional performance. Stat Med. 2005;24:1185-202.

64. Carroll JD, Edwards FH, Marinac-Dabic D, et al. The STS-ACC transcatheter valve therapy national registry: a new partnership and infrastructure for the introduction and surveillance of medical devices and therapies. J Am Coll Cardiol. 2013;62:1026-34.

65. O'Brien SM, Shahian DM, DeLong ER, et al. Quality measurement in adult cardiac surgery: part 2-Statistical considerations in composite measure scoring and provider rating. Ann Thorac Surg. 2007;83:S13-26.

66. Carroll JD, Shuren J, Jensen TS, et al. Transcatheter valve therapy registry is a model for medical device innovation and surveillance. Health Aff (Millwood). 2015;34:328-34.

67. The Society of Thoracic Surgeons. The STS welcome page. Available at: http:// www.sts.org/. Accessed April 2, 2017.

68. STS/ACC TVT Registry. Research: answering critical questions about transcatheter valve replacement and repair procedures. Available at: https://www. ncdr.com/webncdr/tvt/publicpage/research. Accessed April 2, 2017.

69. Mack MJ, Brennan JM, Brindis R, et al. Outcomes following transcatheter aortic valve replacement in the United States. JAMA. 2013;310:2069-77.

70. Grover FL, Vemulapalli S, Carroll JD, et al. 2016 annual report of The Society of Thoracic Surgeons/American College of Cardiology Transcatheter Valve Therapy Registry. J Am Coll Cardiol. 2017;69:1215-30.

71. Messenger JC, Ho KK, Young CH, et al. The National Cardiovascular Data Registry (NCDR) data quality brief: the NCDR data quality program in 2012. J Am Coll Cardiol. 2012;60:1484-8. 
72. Chakravarty T, Sondergaard L, Friedman J, et al. Subclinical leaflet thrombosis in surgical and transcatheter bioprosthetic aortic valves: an observational study. Lancet. 2017;389:2383-92.

73. Alli OO, Booker JD, Lennon RJ, Greason KL, Rihal CS, Holmes DR Jr. Transcatheter aortic valve implantation: assessing the learning curve. JACC Cardiovasc Interv. 2012;5:72-9.

74. D’Ancona G, Pasic M, Unbehaun A, et al. Transapical aortic valve implantation: learning curve with reduced operating time and radiation exposure. Ann Thorac Surg. 2014;97:43-7.

75. Gurevich S, John R, Kelly RF, et al. Avoidi ng the learning curve for transcatheter aortic valve replacement. Cardiol Res Pract. 2017;2017:7524925.

76. Gurvitch R, Tay EL, Wijesinghe N, et al. Transcatheter aortic valve implantation: lessons from the learning curve of the first 270 high-risk patients. Catheter Cardiovasc Interv. 2011;78:977-84.

77. Henn MC, Percival T, Zajarias A, et al. Learning alternative access approaches for transcatheter aortic valve replacement: implications for new transcatheter aortic valve replacement centers. Ann Thorac Surg. 2017;103:1399-405.

78. Kempfert J, Rastan A, Holzhey D, et al. Transapical aortic valve implantation: analysis of risk factors and learning experience in 299 patients. Circulation. 2011;124:S124-9.

79. Lardizabal JA, O'Neill BP, Desai HV, et al. The transaortic approach for transcatheter aortic valve replacement: initial clinical experience in the United States. J Am Coll Cardiol. 2013;61:2341-5.

80. Marmagkiolis K, Arzamendi D, Goktekin O, Cilingiroglu M. Structural heart interventions training in Europe. Int J Cardiol. 2016;202:532-4.

81. Novick RJ, Fox SA, Kiaii BB, et al. Analysis of the learning curve in telerobotic, beating heart coronary artery bypass grafting: a 90 patient experience. Ann Thorac Surg. 2003;76:749-53.

82. Novick RJ, Fox SA, Stitt LW, et al. Cumulative sum failure analysis of a policy change from on-pump to off-pump coronary artery bypass grafting. Ann Thorac Surg. 2001;72:S1016-21.

83. Steiner SH, Cook RJ, Farewell VT, Treasure T. Monitoring surgical performance using risk-adjusted cumulative sum charts. Biostatistics. 2000;1:441-52.

84. Grunkemeier GL, Wu YX, Furnary AP. Cumulative sum techniques for assessing surgical results. Ann Thorac Surg. 2003;76:663-7.

85. Blackstone EH. Monitoring surgical performance. J Thorac Cardiovasc Surg. 2004; 128:807-10.

86. Lovegrove J, Valencia O, Treasure T, Sherlaw-Johnson C, Gallivan S. Monitoring the results of cardiac surgery by variable life-adjusted display. Lancet. 1997;350:1128-30.

87. de Leval MR, Francois K, Bull C, Brawn W, Spiegelhalter D. Analysis of a cluster of surgical failures. Application to a series of neonatal arterial switch operations. J Thorac Cardiovasc Surg. 1994;107:914-23; discussion 23-4.

88. de Biasi AR, Paul S, Nasar A, Girardi LN, Salemi A. National analysis of shortterm outcomes and volume-outcome relationships for transcatheter aortic valve replacement in the era of commercialization. Cardiology. 2016;133:58-68.

89. Arai T, Romano M, Lefevre T, et al. Impact of procedural volume on outcome optimization in transaortic transcatheter aortic valve implantation. Int J Cardiol. 2016;223:292-6.

90. Verma DR, Pershad Y, Pershad A, Fang K, Gellert G, Morris MF. Impact of institutional volume and experience with CT interpretation on sizing of transcatheter aortic valves: a multicenter retrospective study. Cardiovasc Revasc Med. 2016;17:566-70.

91. Thourani VH, Suri RM, Gunter RL, et al. Contemporary real-world outcomes of surgical aortic valve replacement in 141,905 low-risk, intermediate-risk, and high-risk patients. Ann Thorac Surg. 2015;99:55-61.

92. Johnston DR, Atik FA, Rajeswaran J, et al. Outcomes of less invasive J-incision approach to aortic valve surgery. J Thorac Cardiovasc Surg. 2012;144: 852-858.e3

93. Birkmeyer JD, Stukel TA, Siewers AE, Goodney PP, Wennberg DE, Lucas FL. Surgeon volume and operative mortality in the United States. $N$ Engl J Med. 2003;349:2117-27.

94. Patel HJ, Herbert MA, Drake DH, et al. Aortic valve replacement: using a statewide cardiac surgical database identifies a procedural volume hinge point. Ann Thorac Surg. 2013;96:1560-5; discussion 1565-6.

95. Dewey TM, Herbert MA, Ryan WH, et al. Influence of surgeon volume on outcomes with aortic valve replacement. Ann Thorac Surg. 2012;93:1107-12; discussion 1112-3.
96. McNeely C, Markwell S, Filson K, Hazelrigg S, Vassileva C. Effect of hospital volume on prosthesis use and mortality in aortic valve operations in the elderly. Ann Thorac Surg. 2016;101:585-90.

97. Gonzalez AA, Dimick JB, Birkmeyer JD, Ghaferi AA. Understanding the volume-outcome effect in cardiovascular surgery: the role of failure to rescue. JAMA Surg. 2014;149:119-23.

98. Khera R, Pandey A, Koshy T, et al. Role of hospital volumes in identifying lowperforming and high-performing aortic and mitral valve surgical centers in the United States. JAMA Cardiol. 2017;2:1322-31.

99. Birkmeyer JD, Siewers AE, Finlayson EV, et al. Hospital volume and surgical mortality in the United States. N Engl J Med. 2002;346:1128-37.

100. Goodney PP, Lucas FL, Birkmeyer JD. Should volume standards for cardiovascular surgery focus only on high-risk patients? Circulation. 2003;107:384-7.

101. Hughes GC, Zhao Y, Rankin JS, et al. Effects of institutional volumes on operative outcomes for aortic root replacement in North America. J Thorac Cardiovasc Surg. 2013;145:166-70.

102. Soppa G, Abdulkareem N, Smelt J, Van Besouw JP, Jahangiri M. High-volume practice by a single specialized team reduces mortality and morbidity of elective and urgent aortic root replacement. Aorta (Stamford). 2013;1:40-4.

103. Sievers HH, Stierle U, Charitos EI, et al. A multicentre evaluation of the autograft procedure for young patients undergoing aortic valve replacement: update on the German Ross Registry. Eur J Cardiothorac Surg. 2016;49:212-8

104. Johnston DR, Soltesz EG, Vakil N, et al. Long-term durability of bioprosthetic aortic valves: implications from 12,569 implants. Ann Thorac Surg. 2015;99:1239-47.

105. Bourguignon T, El Khoury R, Candolfi P, et al. Very long-term outcomes of the Carpentier-Edwards perimount aortic valve in patients aged 60 or younger. Ann Thorac Surg. 2015;100:853-9.

106. Potter DD, Sundt TM 3rd, Zehr KJ, et al. Operative risk of reoperative aortic valve replacement. J Thorac Cardiovasc Surg. 2005;129:94-103.

107. Chhatriwalla AK, Allen KB, Saxon JT, et al. Bioprosthetic valve fracture im proves the hemodynamic results of valve-in-valve transcatheter aortic valve replacement. Circ Cardiovasc Interv. 2017;10:e005216.

108. Allen KB, Chhatriwalla AK, Cohen DJ, et al. Bioprosthetic valve fracture to facilitate transcatheter valve-in-valve implantation. Ann Thorac Surg. 2017; 104:1501-8.

109. Dhareshwar J, Sundt TM 3rd, Dearani JA, Schaff HV, Cook DJ, Orszulak TA Aortic root enlargement: what are the operative risks? J Thorac Cardiovasc Surg. 2007; 134:916-24.

110. Grubitzsch H, Zobel S, Christ T, et al. Redo procedures for degenerated stentless aortic xenografts and the role of valve-in-valve transcatheter techniques. Eur $J$ Cardiothorac Surg. 2017;51:653-9.

111. Glaser N, Jackson V, Holzmann MJ, Franco-Cereceda A, Sartipy U. Aortic valve replacement with mechanical vs. biological prostheses in patients aged 50-69 years. Eur Heart J. 2016;37:2658-67.

112. Puskas J, Gerdisch M, Nichols D, et al. Reduced anticoagulation after mechanical aortic valve replacement: interim results from the prospective randomized on-X valve anticoagulation clinical trial randomized Food and Drug Administration investigational device exemption trial. J Thorac Cardiovasc Surg. 2014; 147:1202-10; discussion 1210-1.

113. Koertke H, Zittermann A, Wagner O, et al. Telemedicine-guided, very low-dose international normalized ratio self-control in patients with mechanical heart valve implants. Eur Heart J. 2015;36:1297-305.

114. Badhwar V, Ofenloch JC, Rovin JD, van Gelder HM, Jacobs JP. Noninferiority of closely monitored mechanical valves to bioprostheses overshadowed by early mortality benefit in younger patients. Ann Thorac Surg. 2012;93:748-53.

115. Sharma V, Suri RM, Dearani JA, et al. Expanding relevance of aortic valve repair-is earlier operation indicated? J Thorac Cardiovasc Surg. 2014;147: $100-7$.

116. Ouzounian M, Rao V, Manlhiot C, et al. Valve-sparing root replacement compared with composite valve graft procedures in patients with aortic root dilation. J Am Coll Cardiol. 2016;68:1838-47.

Key Words: Expert Consensus Systems of Care Document, accreditation, outcomes measures, registry, surgical aortic valve repair, transcatheter aortic valve repair 


\section{APPENDIX 1. MEASUREMENT STATISTICAL APPROACHES}

\section{TAVR Program Performance Requirements:} Minimum Quality Benchmarks for Each TAVR Site

Because TAVR is an evolving form of treatment impacted by continual improvement in advanced devices and simplification of procedures, the outcome thresholds for quality of care will be moving targets. Therefore, the mechanism of data presentation and interpretation will be determined using risk-adjusted individual and composite outcomes based on the accumulation of data through the 4 most current rolling quarters of data, presented in a variety of formats including box and whisker plots (which do not account for random sampling variation, especially at lower volume programs), funnel plots (which visually demonstrate sampling variation at low volumes, and accommodate various control limits [eg, 90\%, 95\%]), and statistical hypothesis testing for risk-adjusted measures (as expected, better than expected, worse than expected) Data presentation and analyses will be continuously updated based on the most recent data.

\section{Statistical Challenge of Correctly Identifying Poor- Performing TAVR Programs With Low Annual Volumes}

The writing committee acknowledges the difficulty in correctly assessing the performance of low-volume programs. The confidence intervals around a binary event such as death increase dramatically at lower volumes, producing a "funnel on its side" appearance with the wide end at low volumes. Because of these wide confidence intervals, the results from a low-volume (small sample size) program have substantial statistical uncertainty. It is difficult to ascertain from this sample what the true underlying performance is of such a program. In contrast, the narrower confidence limits inherent with high-volume programs (large sample size) allows for a more certain estimate of their true underlying performance, enabling their observed performance to be compared with what would be expected for their case mix. Restating, some low-volume programs could potentially have better or worse than expected performance over the long term with additional observations, but we cannot currently classify them as outliers due to their small sample sizes.

To help mitigate the statistical challenges of evaluating low-volume programs, a 3-year rolling data time frame is recommended to provide more observations and to better assess true differences in outcomes. In the future, composite, multidimensional performance measures will further increase the effective number of endpoints.

Consistent with standard profiling practice, the committee recommends identifying true quality outliers as having risk-adjusted performance that is statistically significantly different than expected for their case mix, based on the overall performance of the benchmark population of providers for similar patients. Statistical significance is usually determined by assessing whether the $95 \%$ confidence intervals around the provider's point estimate of risk-adjusted mortality include the overall average mortality, or whether the confidence intervals around their ratio of observed to expected mortality include unity (one). Low-volume centers, particularly newer programs with less than 3 years of rolling data, need to be vigilant in their own internal assessments if "signals" or "trends" for poor quality are appreciated despite not reaching a 95\% confidence level due to the challenge of accurate assessment of low-volume center quality.

To provide larger sample sizes and greater statistical power, there will be a 2-year grace period for new sites to accumulate a sufficient number of cases before full accountability of outcomes is required. Prior to the completion of the 2-year grace period, worrisome trends in suboptimal outcomes should be addressed with action plans to enhance clinical performance. A minimum yearly volume of cases is recommended to ensure program process resources are maintained and statistical relevance of outcomes.

If problematic performance is suggested by any of the performance monitoring approaches listed in the previous text, immediate and robust investigation and remediation is indicated. The document outlines requirements for a monthly mortality conference, quarterly sessions to analyze TVT Registry outcomes, and semiannual STS National Database outcomes, with documentation of process and corrective initiatives for improvement of individual and composite outcomes. For risk-adjusted outcomes or funnel plots, less restrictive confidence intervals or control limits (eg, 90\%) may be used as warning signals that warrant internal investigation and performance improvement, whereas $95 \%$ intervals or control limits may be used to more confidently identify outliers. In the latter case, the institution should sponsor an external review to assess the program and make performance improvement recommendations. 
APPENDIX 2. AUTHOR RELATIONSHIPS WITH INDUSTRY AND OTHER ENTITIES (RELEVANT)—2018 AATS/ACC/SCAI/STS EXPERT CONSENSUS SYSTEMS OF CARE DOCUMENT: OPERATOR AND INSTITUTIONAL RECOMMENDATIONS AND REQUIREMENTS FOR TRANSCATHETER AORTIC VALVE REPLACEMENT

\begin{tabular}{|c|c|c|c|c|c|c|c|c|}
\hline Committee member & Employment & Representing & Consultant & Speakers bureau & $\begin{array}{c}\text { Ownership/partnership/ } \\
\text { principal }\end{array}$ & Personal research & $\begin{array}{c}\text { Institutional, } \\
\text { organizational, } \\
\text { or other financial benefit }\end{array}$ & Expert witness \\
\hline Joseph E. Bavaria (Co-Chair) & $\begin{array}{l}\text { Hospital of the University } \\
\text { of Pennsylvania- } \\
\text { Director, Thoracic Aortic } \\
\text { Surgery Program }\end{array}$ & STS & None & None & None & None & None & None \\
\hline Carl L. Tommaso (Co-Chair) & $\begin{array}{l}\text { NorthShore University } \\
\text { HealthSystem_-Associate } \\
\text { Director, Cardiac } \\
\text { Catheterization } \\
\text { Laboratories } \\
\text { Rush Medical College_- } \\
\text { Associate Professor } \\
\text { of Medicine }\end{array}$ & SCAI & None & None & None & None & None & None \\
\hline Ralph G. Brindis & $\begin{array}{l}\text { University of California, San } \\
\text { Francisco-Clinical } \\
\text { Professor of Medicine } \\
\text { ACC National Cardiovascular } \\
\text { Data Registry—Senior } \\
\text { Medical Officer, External } \\
\text { Affairs }\end{array}$ & ACC & None & None & None & $\begin{array}{l}\text { - GE Healthcare (DSMB) } \\
\text { - State of California OSHPD } \\
\text { (DSMB)* }\end{array}$ & $\begin{array}{l}\text { - } \mathrm{ACC} \dagger \\
\text { - FDA CV device panel }\end{array}$ & None \\
\hline John D. Carroll & $\begin{array}{l}\text { University of Colorado } \\
\text { Denver-Professor of } \\
\text { Medicine; Director, } \\
\text { Interventional Cardiology }\end{array}$ & $\mathrm{ACC}$ & None & None & None & $\begin{array}{l}\text { - St. Jude Medical, } \\
\text { RESPECT, Steering } \\
\text { Committee } † \\
\text { ACP Trial, Steering } \\
\text { Committee } \\
\text { - Tendyne (DSMB) }\end{array}$ & None & None \\
\hline G. Michael Deeb & $\begin{array}{l}\text { University of Michigan } \\
\text { Cardiovascular Center-- } \\
\text { Herbert Sloan Collegiate } \\
\text { Professor of Cardiac } \\
\text { Surgery; Director, } \\
\text { Multidisciplinary } \\
\text { Aortic Clinic }\end{array}$ & AATS & None & None & None & None & None & None \\
\hline Ted E. Feldman & $\begin{array}{l}\text { Evanston Hospital, North } \\
\text { Shore University Health } \\
\text { System-Director, } \\
\text { Cardiac Catheterization } \\
\text { Laboratory }\end{array}$ & SCAI & $\begin{array}{l}\text { - Abbott } \\
\text { - Boston Scientific } \\
\text { - Edwards Lifesciences }\end{array}$ & None & None & None & None & None \\
\hline Thomas G. Gleason & $\begin{array}{l}\text { University of Pittsburgh } \\
\text { School of Medicine- } \\
\text { Ronald V. Pellegrini } \\
\text { Professor and Chief, } \\
\text { Division of } \\
\text { Cardiac Surgery }\end{array}$ & STS & None & None & None & None & None & None \\
\hline
\end{tabular}




\begin{tabular}{|c|c|c|c|c|c|c|c|c|}
\hline \multicolumn{9}{|c|}{ PPENDIX 2. Continued } \\
\hline Committee member & Employment & Representing & Consultant & Speakers bureau & $\begin{array}{c}\text { Ownership/partnership/ } \\
\text { principal }\end{array}$ & Personal research & $\begin{array}{c}\text { Institutional, } \\
\text { organizational, } \\
\text { or other financial benefit }\end{array}$ & Expert witness \\
\hline Eric M. Horlick & $\begin{array}{l}\text { Toronto General Hospital } \\
\text { University of Toronto-Peter } \\
\text { Munk Chair in Congenital } \\
\text { and Structural Heart } \\
\text { Disease Intervention; } \\
\text { Associate Professor of } \\
\text { Medicine }\end{array}$ & SCAI & $\begin{array}{l}\text { - Edwards Lifesciences } \dagger \\
\text { - Medtronic } \dagger \\
\text { - St. Jude Medical } \uparrow\end{array}$ & None & None & None & None & None \\
\hline Clifford J. Kavinsky & $\begin{array}{l}\text { Rush University Medical } \\
\text { Center-Professor of } \\
\text { Medicine }\end{array}$ & SCAI & None & None & None & None & None & None \\
\hline Dharam J. Kumbhani & $\begin{array}{l}\text { University of Texas } \\
\text { Southwestern Medical } \\
\text { Center-Associate } \\
\text { Professor Internal } \\
\text { Medicine }\end{array}$ & ACC & None & None & None & None & None & None \\
\hline D. Craig Miller & $\begin{array}{l}\text { Stanford University Medical } \\
\text { Center-Thelma and } \\
\text { Henry Doelger Professor } \\
\text { in Cardiovascular Surgery }\end{array}$ & AATS & - Medtronic & None & None & $\begin{array}{l}\text { - Abbott } \dagger \\
\text { - Edwards Lifesciences } \dagger \\
\text { - Medtronic Core Valve }\end{array}$ & Edwards Lifesciences* & None \\
\hline A. Allen Seals & $\begin{array}{l}\text { North Florida Cardiovascular } \\
\text { Research }\end{array}$ & $\mathrm{ACC}$ & None & None & None & None & None & None \\
\hline David M. Shahian & $\begin{array}{l}\text { Harvard Medical School_- } \\
\text { Professor of Surgery } \\
\text { Massachusetts General } \\
\text { Hospital Center for } \\
\text { Quality and Safety_-Vice } \\
\text { President } \\
\text { Codman Center for Clinical } \\
\text { Effectiveness in Surgery_- } \\
\text { Associate Director }\end{array}$ & STS & None & None & None & None & $\begin{array}{l}\text { - NQF* } \\
\text { - PCPI and NQRN* } \\
\text { - STS* }\end{array}$ & None \\
\hline Richard J. Shemin & $\begin{array}{l}\text { Department of Surgery, } \\
\text { Ronald Reagan UCLA } \\
\text { Medical Center-Chief } \\
\text { of Cardiac Surgery and } \\
\text { Vice-Chair } \\
\text { David Geffen School of } \\
\text { Medicine-Co-Director }\end{array}$ & STS & $\begin{array}{l}\text { - Edwards Lifesciences } \\
\text { - Sorin Group }\end{array}$ & None & None & None & None & $\begin{array}{l}\text { Defendant, } \\
\text { mitral valve } \\
\text { malpractice, } \\
2016\end{array}$ \\
\hline Thoralf M. Sundt, III & $\begin{array}{l}\text { Massachusetts General } \\
\text { Hospital—Chief, Division } \\
\text { of Cardiac Surgery; } \\
\text { Director, Corrigan } \\
\text { Minehan Heart Center }\end{array}$ & AATS & None & None & None & None & None & $\begin{array}{l}\text { Defendant, aortic } \\
\text { dissection, } 2016\end{array}$ \\
\hline
\end{tabular}




\begin{tabular}{|c|c|c|c|c|c|c|c|c|}
\hline Committee member & Employment & Representing & Consultant & Speakers bureau & $\begin{array}{c}\text { Ownership/partnership/ } \\
\text { principal }\end{array}$ & Personal research & $\begin{array}{c}\text { Institutional, } \\
\text { organizational, } \\
\text { or other financial benefit }\end{array}$ & Expert witness \\
\hline Vinod H. Thourani & $\begin{array}{l}\text { Medstar Heart and } \\
\text { Vascular Institute-Chair, } \\
\text { Department of } \\
\text { Cardiac Surgery } \\
\text { Washington Hospital } \\
\text { Center-Professor } \\
\text { of Surgery }\end{array}$ & STS & $\begin{array}{l}\text { - Edwards Lifesciences } \\
\text { - St. Jude Medical }\end{array}$ & None & None & - Abbott & None & None \\
\hline
\end{tabular}

This table represents the relationships of committee members with industry and other entities that were determined to be relevant to this document. These relationships were reviewed and updated in conjunction with all meetings and/ or conference calls of the writing committee during the document development process. The table does not necessarily reflect relationships with industry at the time of publication. A person is deemed to have a significant interest in a business if the interest represents ownership of $\geq 5 \%$ of the voting stock or share of the business entity, or ownership of $\geq \$ 5,000$ of the fair market value of the business entity; or if funds received by the person from the business entity exceed $5 \%$ of the person's gross income for the previous year Relationships that exist with no financial benefit are also included for the purpose of transparency. Relationships in this table are modest unless otherwise noted. According to the ACC, a person has a relevant relationship IF: a) the relationship or interest relates to the same or similar subject matter, intellectual property, or asset, topic, or issue addressed in the document; or b) the company/entity (with whom the relationship exists) makes a drug, drug class, or device addressed in the document or makes a competing drug or device addressed in the document; or c) the person or a member of the person's household, has a reasonable potential for financial, professional, or other personal gain or loss as a result of the issues/content addressed in the document. STS, Society of Thoracic Surgeons; SCAI, Society for Cardiovascular Angiography and Interventions; ACC, American College of Cardiology; DSMB, Data Safety Monitoring Board; OSHPD, Office of Statewide Health Planning and Development; FDA, U.S. Food and Drug Administration; $C V$, cardiovascular; ACP, American College of Physicians; AATS, American Association for Thoracic Surgery; NOF, National Quality Forum; PCPI, Physician Consortium for Performance Improvement; NORN, National Quality Registry Network. *No financial benefit. $\nmid$ Significant relationship.






\begin{tabular}{|c|c|c|}
\hline Reviewer & Representation & Employment \\
\hline Frank V. Aguirre & Official Reviewer-ACC BOG & Prairie Cardiovascular Consultants_-Interventional Cardiologist \\
\hline Pavan Atluri & Official Reviewer-AATS & $\begin{array}{l}\text { University of Pennsylvania-Assistant Professor of Surgery; } \\
\text { Director, Cardiac Transplantation and Mechanical Circulatory } \\
\text { Assist; Program Director, Minimally Invasive and Robotic } \\
\text { Cardiac Surgery Program, Division of Cardiovascular Surgery, } \\
\text { Department of Surgery }\end{array}$ \\
\hline Mauricio G. Cohen & Official Reviewer-SCAI & $\begin{array}{l}\text { University of Miami Hospital-Associate Professor of Medicine; } \\
\text { Director, Cardiac Catheterization Laboratory }\end{array}$ \\
\hline Larry S. Dean & Official Reviewer-SCAI & $\begin{array}{l}\text { University of Washington School of Medicine-Professor of } \\
\text { Medicine and Surgery; UW Medicine Regional Heart Center- } \\
\text { Director }\end{array}$ \\
\hline John Ikonomidis & Official Reviewer-AATS & $\begin{array}{l}\text { University of North Carolina School of Medicine at Chapel Hill- } \\
\text { Chief, Division of Cardiothoracic Surgery }\end{array}$ \\
\hline Chad Kliger & Official Reviewer-SCAI & $\begin{array}{l}\text { Lenox Hill Hospital-Director, Structural Heart Disease, } \\
\text { Cardiovascular Medicine; Hofstra/Northwell—Assistant } \\
\text { Professor, Donald and Barbara Zucker School of Medicine }\end{array}$ \\
\hline Thomas E. MacGillivray & Official Reviewer-STS & $\begin{array}{l}\text { DeBakey Heart \& Vascular Center-Chief, Division of Cardiac } \\
\text { Surgery \& Thoracic Transplant Surgery }\end{array}$ \\
\hline James K. Min & $\begin{array}{l}\text { Official Reviewer-Task } \\
\text { Force on Expert Consensus } \\
\text { Decision Pathways }\end{array}$ & $\begin{array}{l}\text { Dalio Institute of Cardiovascular Imaging at New York Presbyterian } \\
\text { Hospital—Professor of Radiology and Medicine; Director }\end{array}$ \\
\hline Richard L. Prager & Official Reviewer-STS & $\begin{array}{l}\text { University of Michigan-Director and Clinical Lead, Samuel and } \\
\text { Jean Frankel Cardiovascular Center }\end{array}$ \\
\hline Joseph F. Sabik III & Official Reviewer-STS & $\begin{array}{l}\text { University Hospitals Cleveland Medical Center-Chair, } \\
\text { Department of Surgery, Surgeon-in-Chief }\end{array}$ \\
\hline Elaine Tseng & Official Reviewer-AATS & $\begin{array}{l}\text { University of California at San Francisco Medical Center- } \\
\text { Professor of Surgery; San Francisco VA Medical Center-Chief } \\
\text { of Cardiothoracic Surgery }\end{array}$ \\
\hline Sandra V. Abramson & Organizational Reviewer-ACP & $\begin{array}{l}\text { Lankenau Heart Pavilion-Medical Director, Cardiovascular } \\
\text { Imaging Center; Director, Interventional Echocardiography }\end{array}$ \\
\hline Louann Bailey & Organizational Reviewer-AANP & $\begin{array}{l}\text { Inpatient Medical Services Inc., Summa Health System, Akron, } \\
\text { Ohio- Hospitalist Nurse Practitioner }\end{array}$ \\
\hline Mary Beth Brady & Organizational Reviewer-SCA & $\begin{array}{l}\text { Johns Hopkins University School of Medicine-Vice Chair for } \\
\text { Education, Department of Anesthesiology and Critical Care } \\
\text { Medicine; Associate Professor, Anesthesiology and Critical Care } \\
\text { Medicine }\end{array}$ \\
\hline Brian B. Ghoshhajra & Organizational Reviewer-SCCT & $\begin{array}{l}\text { Massachusetts General Hospital—Service Chief, Cardiovascular } \\
\text { Imaging; Program Director, Cardiac Imaging Fellowship }\end{array}$ \\
\hline Uzoma N. Ibebuogu & Organizational Reviewer-ABC & $\begin{array}{l}\text { University of Tennessee Health Sciences Center-Associate } \\
\text { Professor of Medicine, Division of Cardiovascular Diseases; } \\
\text { Methodist University Hospital-Director of Structural Heart } \\
\text { Disease Intervention }\end{array}$ \\
\hline Stephen H. Little & Organizational Reviewer-ASE & $\begin{array}{l}\text { The Methodist DeBakey Heart Center-Associate Professor, } \\
\text { Department of Cardiology }\end{array}$ \\
\hline Amy E. Simone & Organizational Reviewer-AAPA & $\begin{array}{l}\text { Emory University Hospital Midtown—Physician Assistant, } \\
\text { Department of Cardiothoracic Surgery Structural Heart \& Valve } \\
\text { Program }\end{array}$ \\
\hline Andrew Wang & Organizational Reviewer-AHA & $\begin{array}{l}\text { Duke University Medical Center-Professor of Medicine; Director, } \\
\text { Cardiovascular Disease Fellowship Program }\end{array}$ \\
\hline Eric R. Bates & Content Reviewer-Individual Expert & University of Michigan-Professor of Medicine \\
\hline
\end{tabular}


APPENDIX 3. Continued

\begin{tabular}{|c|c|c|}
\hline Reviewer & Representation & Employment \\
\hline Ralph Brindis & Content Reviewer-NCDR Management Board & $\begin{array}{l}\text { University of California, San Francisco-Clinical Professor, } \\
\text { Department of Medicine \& the Philip R. Lee Institute for Health } \\
\text { Policy Studies; ACC National Cardiovascular Data Registry- } \\
\text { Senior Medical Officer, External Affairs }\end{array}$ \\
\hline Michael S. Firstenberg & Content Reviewer-Surgeons' Council & $\begin{array}{l}\text { Northeast Ohio Medical Universities-Director, Adult ECMO } \\
\text { Program; Director, Surgical Research; Associate Professor of } \\
\text { Surgery and Integrative Medicine; Summa Akron City Hospital- } \\
\text { Cardiothoracic Surgeon }\end{array}$ \\
\hline Linda D. Gillam & Content Reviewer-Health Affairs Committee & $\begin{array}{l}\text { Morristown Medical Center-Chair, Department of Cardiovascular } \\
\text { Medicine }\end{array}$ \\
\hline Henry S. Jennings III & Content Reviewer-ACC Imaging Council & $\begin{array}{l}\text { Vanderbilt University Medical Center-Assistant Professor of } \\
\text { Medicine, Cardiovascular Division }\end{array}$ \\
\hline Patricia Keegan & Content Reviewer-ACC Roundtable Participant & $\begin{array}{l}\text { Emory Structural Heart and Valve Center-Structural Heart } \\
\text { Coordinator }\end{array}$ \\
\hline Thomas M. Maddox & $\begin{array}{l}\text { Content Reviewer-Task Force on Health } \\
\text { Policy Statements and Systems of Care }\end{array}$ & $\begin{array}{l}\text { Washington University School of Medicine/BJC Healthcare- } \\
\text { Director, Health Systems Innovation Lab (HSIL); Washington } \\
\text { University School of Medicine-Professor of Medicine } \\
\text { (Cardiology) }\end{array}$ \\
\hline Elizabeth N. Perpetua & Content Reviewer-ACC Roundtable Participant & $\begin{array}{l}\text { University of Washington Medical Center-Director, Structural } \\
\text { Heart Services; Associate Director, Center for Cardiovascular } \\
\text { Emerging Therapies; Teaching Associate, Cardiology and } \\
\text { Cardiac Surgery }\end{array}$ \\
\hline William A. Van Decker & Content Reviewer-Health Affairs Committee & Temple University Hospital-Assistant Professor of Medicine \\
\hline Frederick G. P. Welt & Content Reviewer-Interventional Council & $\begin{array}{l}\text { University of Utah Health Sciences Center-Director, } \\
\text { Interventional Cardiology }\end{array}$ \\
\hline
\end{tabular}

$\overline{A C C}$, American College of Cardiology; BOG, Board of Governors; AATS, American Association for Thoracic Surgery; SCAI, Society for Cardiac Angiography and Interventions; STS, Society of Thoracic Surgeons; ACP, American College of Physicians; AANP, American Association of Nurse Practitioners; SCA, Society of Cardiovascular Anesthesiologists; SCCT, Society of Cardiovascular Computed Tomography; ABC, Association of Black Cardiologists; ASE, American Society of Echocardiography; AAPA, American Association of Physician Assistants; AHA, American Heart Association; NCDR, National Cardiovascular Data Registry.

\section{APPENDIX 4. ABBREVIATIONS}

$\mathrm{ACC}=$ American College of Cardiology

AATS $=$ American Association for Thoracic Surgery

$\mathrm{AS}=$ aortic stenosis

$\mathrm{AUC}=$ appropriate use criteria

$\mathrm{AVR}=$ aortic valve replacement

$\mathrm{CMS}=$ Center for Medicare and Medicaid Services

$\mathrm{KCCQ}=$ Kansas City Cardiomyopathy Questionnaire

MDT $=$ multidisciplinary team

NCD $=$ National Coverage Determination
$\mathrm{QoL}=$ quality of life

SAVR $=$ surgical aortic valve replacement

SCAI $=$ Society for Cardiovascular Angiography and Interventions

$\mathrm{SDM}=$ shared decision making

STS $=$ Society of Thoracic Surgeons

TAVR $=$ transcatheter aortic valve replacement

$\mathrm{TVT}=$ transcatheter valve therapies

$\mathrm{VHD}=$ valvular heart disease 